Bundesgesundheitsbl 2009 · 52:699-714 DOI 10.1007/s00103-009-0874-9

Online publiziert: 19. Juni 2009

๑) Springer-Verlag 2009

K. Stark · M. Niedrig · W. Biederbick · H. Merkert • J. Hacker

Robert Koch-Institut, Berlin

\title{
Die Auswirkungen des Klimawandels
}

\section{Welche neuen Infektionskrankheiten und gesundheitlichen Probleme sind zu erwarten?}

Interesses. Die erste Konferenz der Weltgesundheitsordnung (WHO) zu den Auswirkungen des globalen Klimawandels auf die menschliche Gesundheit im April 2008 in Bonn betonte die Auswirkungen des Klimawandels auf die Verbreitung von Infektionskrankheiten.

Mit Blick auf Deutschland betrifft dies sowohl Infektionserreger, die bereits endemisch sind (zum Beispiel Hantaviren, Zecken-übertragene Erreger wie Borrelien und FSME-Virus, durch Lebensmittel und Wasser übertragene Erreger), als auch neue, bisher in Deutschland nicht heimische Erreger, die über den Transport von Menschen, Tieren oder Waren eingeschleppt werden können.

Der Chikungunya-Ausbruch im Jahr 2007 in Norditalien, der erstmalige Nachweis eines Chikungunya-Überträgers,
Aedes albopictus ("Tigermücke"), 2007 in Deutschland und die andauernde WestNile-Epidemie in Nord- und Südamerika deuten an, dass Klimawandel und davon beeinflusste ökologische Faktoren sowie zunehmender globaler Personen-, Tier- und Güterverkehr auch in Deutschland autochthone Ausbrüche von Infektionskrankheiten ermöglichen könnten, deren Verbreitung früher auf tropische und subtropische Regionen beschränkt war. Gefahr droht in erster Linie von Infektionen, an deren Übertragung Insekten und andere Arthropoden, Nagetiere oder Vögel beteiligt sind, da deren Populationsstärke und Übertragungspotenzial in besonderem Maße von Klimafaktoren beeinflusst werden. Mit bedingt durch den Klimawandel breiten sich durch Vektoren übertragene Infektionskrankheiten wie Gelbzum Ende dieses Jahrhunderts die Temperaturen in Deutschland um weitere $2,5^{\circ} \mathrm{C}$ bis $3,5^{\circ} \mathrm{C}$ steigen [2]. Besonders stark würde die Erwärmung in den Winterperioden in Süddeutschland ausfallen.

Zusätzlich wurde weltweit eine Zunahme von extremen Wetterereignissen verzeichnet, die in engen Zusammenhang mit dem Klimawandel gebracht werden. Stürme, Fluten, Dürreperioden und Hitzewellen fordern bereits jetzt tausende Todesopfer weltweit. Die Häufigkeit und die Intensität dieser extremen Wetterereignisse werden auch bei uns zunehmen. Von wahrscheinlich größerer Bedeutung als die direkten Folgen werden langfristig jedoch die indirekten Folgen einer anthropogenen Klimaänderung für die menschliche Gesundheit sein. Hierbei stehen insbesondere die Infektionskrankheiten im Mittelpunkt des

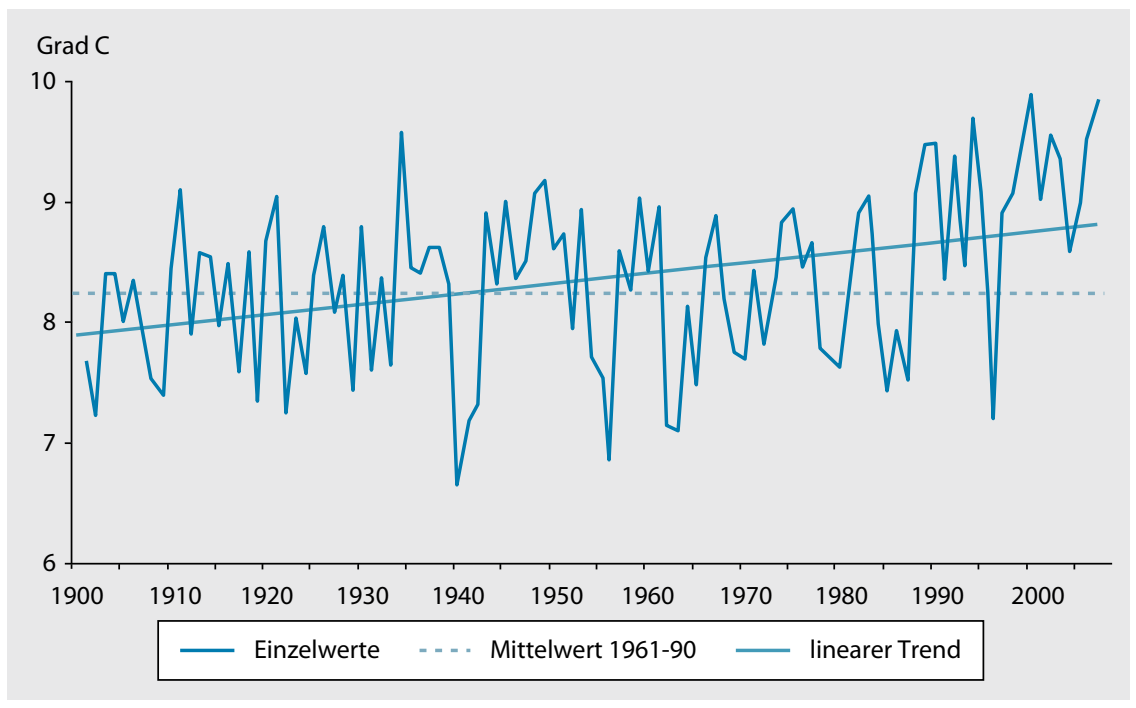

Abb. 1 A Temperaturanstieg in Deutschland 1901-2007 [Quelle: Deutscher Wetterdienst (2008)] 
fieber, Dengue-Fieber und Malaria in vielen Regionen der Erde zunehmend aus. Ein Vordringen und Überleben von bestimmten Vektoren und/oder Erregern in gemäBigten Zonen wie Deutschland wird durch die globale Erwärmung ermöglicht.

Auch wenn viele Zusammenhänge zwischen Infektionskrankheiten und dem Klimawandel noch nicht im Detail zu belegen sind, so zeigen erste Trends, dass Deutschland sich auf diese Problematik einstellen muss. Im Folgenden werden für die wichtigsten klimasensitiven Krankheiten der aktuelle Kenntnisstand zur aktuellen Verbreitung und Häufigkeit in Deutschland kurz dargestellt und unter dem Szenario einer zunehmenden Erwärmung das zu erwartende Bedrohungspotenzial für die Bevölkerung eingeschätzt. Diese Prognosen resultieren derzeit noch aus geringen $\mathrm{Da}$ tenmengen. Am Ende des Artikels skizzieren wir den Handlungs- und Forschungsbedarf für Deutschland im Bereich Klimawandel und Infektionskrankheiten.

\section{Klimawandel und nicht- infektiöse Krankheiten}

Klimatische Veränderungen können sich auch auf das Vorkommen von nicht-infektiösen Krankheiten auswirken (Übersicht 1). Beeinträchtigungen der menschlichen Gesundheit sind möglich durch extreme Wetterereignisse (zum Beispiel Überschwemmungen, Stürme), verstärkte Hitzebelastung, verändertes Auftreten von Luftallergenen, verstärkte bodennahe Ozonbildung und vermehrte Exposition gegenüber UV-Strahlung.

Sturm- und Flutkatastrophen können zu physischen und psychischen Traumatisierungen führen und Hitzewellen zu einer deutlichen Zunahme der Sterblichkeit vor allem bei älteren und chronisch kranken Menschen. Hitzebedingt wird das Herz-Kreislauf-System stärker belastet, die körpereigene Temperaturregulation kann gestört werden, und wenn die Flüssigkeits- und Elektrolytzufuhr unzureichend ist, kann dies insbesondere bei vorgeschädigten multimorbiden Patienten letale Folgen haben. Nach wissenschaftlichen Schätzungen war beispielsweise die Hitzewelle im Sommer 2003 in Westeuropa für 35.000 zusätzliche Todesfälle mitverantwortlich.
Der Klimawandel (zum Beispiel steigende Temperatur, Luftfeuchtigkeit) könnte im längerfristigen Trend auch unabhängig von akuten Hitzewellen die Situation bei Herz-Kreislauf-Erkrankungen in Deutschland verschlechtern.

Bereits in den letzten 30 Jahren haben sich aufgrund der milderen Temperaturen in vielen Gegenden Europas die Pollenflugzeiten um zirka zehn Tage verlängert. Außerdem erwarten Experten durch die $\mathrm{Zu}$ nahme der $\mathrm{CO}_{2}$-Konzentration eine stärkere Pollenemission bei manchen Pflanzen. Allergiker werden deshalb nicht nur über längere Zeiträume, sondern auch quantitativ stärker gegen bestimmte Allergene exponiert sein. Erschwerend ist die zunehmende Schadstoffbelastung der Außenluft in den Ballungsgebieten, die über verschiedene Mechanismen die Allergen-Exposition (zum Beispiel zusätzliche Allergen-Aerosole durch Bindung an Feinstaubpartikel) erhöhen oder die allergische Immunantwort in besonderem Maße aktivieren (stärkere Aktivierung von basophilen Granulozyten durch Dieselrußpartikel) kann.

Der Klimawandel begünstigt auch die Verbreitung von Pflanzen mit starkem allergenem Potenzial nach Deutschland. Als Beispiel sei die Beifuß-Ambrosie (Ambrosia artemisiifolia), genannt, die ursprünglich aus den USA stammt und dort eine der häufigsten und potentesten Allergene ist. Sie hat sich in den letzten Jahren verstärkt in Mitteleuropa ausgebreitet und führt zum sogenannten Spätsommerheuschnupfen (Hauptblütezeit August bis Anfang September), aber auch zu hautallergischen Beschwerden.

Hohe Lufttemperaturen verbunden mit starker Sonneneinstrahlung verstärken die bodennahe Ozonbildung, was bei anhaltender sommerlicher Schönwetterlage zu ozonbedingten gesundheitlichen Problemen führen kann (zum Beispiel Schleimhautreizungen, erhöhte Reagibilität der Atemwege).

\section{Klimawandel und Infektionskrankheiten}

\section{Verbreitung von Vektoren}

Die in der $\bullet$ Tab. 1 aufgelisteten Vektoren stellen nur eine kleine Auswahl möglicher Krankheitsüberträger dar und sind be- züglich der Subspezies nicht weiter differenziert. Die Verbreitung der verschiedenen Infektionskrankheiten ist zwangsläufig von dem Vorhandensein der jeweiligen Überträger abhängig. Darüber hinaus müssen diese Vektoren auch mit dem Infektionserreger produktiv infiziert sein, um diese Infektion auf den Menschen übertragen zu können.

Die Faktoren, die für das Vorkommen und die Dichte der verschiedenen Vektoren verantwortlich sind, sind komplex. Hierbei spielen die klimatischen Faktoren sicherlich eine herausragende Rolle, da sie die Lebensbedingungen für die einzelnen Vektoren, was Temperatur und Nahrungsangebot angeht, direkt beeinflussen. Dieser Einfluss spiegelt sich direkt in den Vermehrungs- und Verbreitungszyklen dieser Vektoren wider und zeigt sich in der zyklischen $\mathrm{Zu}$ - und Abnahme der Vektoren, der teils jahreszeitliche, teils andere Ursachen zugrunde liegen.

Somit haben klimatische Einflüsse einen erheblichen Einfluss auf die Verbreitung der Vektoren in allen Klimazonen. Inwieweit die Anpassung vorhandener Vektoren an veränderte Klimabedingungen bei der Ausbreitung von vektorübertragenen Infektionskrankheiten eine Rolle spielt, ist nicht ausreichend untersucht. Hierbei ist die Fähigkeit eines Vektors entscheidend, als Überträger eines Infektionserregers fungieren zu können. Diese als Vektorkompetenz bezeichnete Fähigkeit bedarf zahlreicher Untersuchungen und ist bisher nur unzureichend verstanden.

Die Verbreitung der Vektoren in subtropischen Gebieten verändert sich im jahreszeitlichen Verlauf von Monsunbeziehungsweise Regenzeit, was gerade für die Vermehrung der Mückenlarven von entscheidender Bedeutung ist. In den nördlichen und südlichen Klimazonen bestimmt der jahreszeitliche Wechsel die Verbreitung der Vektoren. Durch die milderen Winter der letzten Jahre treten die jahreszeitlichen Aktivitätsschwankungen in den Hintergrund und führen, wie bei der durch Zecken übertragenen FSME, zu einem ganzjährigen Infektionsgeschehen. Das Vorhandensein der verschiedenen Vektoren wird häufig erst durch das Auftreten der durch diese übertragenen Infektionserreger wahrgenommen, zumal eine aktive Surveil- 
Bundesgesundheitsbl 2009·52:699-714 DOI 10.1007/s00103-009-0874-9

(c) Springer-Verlag 2009

\section{K. Stark $\cdot$ M. Niedrig $\cdot$ W. Biederbick $\cdot$ H. Merkert $\cdot$ J. Hacker \\ Die Auswirkungen des Klimawandels. Welche neuen Infektionskrankheiten und gesundheitlichen Probleme sind zu erwarten?}

\section{Zusammenfassung}

Ein Temperaturanstieg, aber auch andere klimatische Faktoren und die Zunahme von extremen Wetterereignissen werden Auswirkungen auf die menschliche Gesundheit haben. Neben den unmittelbaren Folgen von Extremereignissen (etwa Hitzetote) sind langfristig auch die indirekten Folgeerscheinungen von großer Bedeutung. Neben einer wahrscheinlichen Zunahme von Allergien und einer Verschlimmerung bereits bestehender Herz-Kreislauf-Erkrankungen sowie Atemwegserkrankungen stehen die Infektionskrankheiten im Blickpunkt. Dies betrifft in Deutschland endemische Infektionserreger, beispielsweise Hantaviren mit ihrem Reservoir in Nagetieren, oder durch Zecken übertragene Borrelia-burgdorferi-Spezies und FSME-Viren, aber auch durch Lebensmittel und Wasser übertragene Erreger. Milde Winter in Verbindung mit einem klim- abedingten reichhaltigeren Nahrungsangebot können zu wachsenden Nagetierpopulationen und nachfolgenden Hantavirus-Epidemien führen. Statistische Analysen zeigen einen deutlichen Zusammenhang zwischen Temperatur und der Häufigkeit Lebensmittel-übertragener Zoonoseerreger (zum Beispiel Campylobacter). Ein Leptospiroseausbruch bei Erdbeerpflückern in Deutschland wurde durch vorausgehende Starkregenfälle begünstigt. Eine besondere Gefahr geht von Erregern aus, die bisher in Deutschland nicht heimisch sind, aber durch erkrankte Menschen, Vektoren und Reservoirtiere verstärkt eingeschleppt werden können. Bei fortschreitender Erwärmung finden sowohl die Vektoren als auch einige Erreger bessere Bedingungen für die autochthone Ausbreitung. Hier sind vor allem die durch Stechmücken übertragenen Krankheiten wie Chi-

\section{Climate changes and emerging diseases. What new infectious diseases and health problem can be expected?}

\section{Abstract}

Increasing temperatures, but also other climatic factors, will have an impact on human health. Apart from the direct consequences of extreme weather conditions (e.g., heat-related fatalities), indirect health consequences in the long-term are also of great importance. In addition to a likely increase in allergic diseases and additional complications in the course of cardiovascular and respiratory diseases, infectious diseases are of particular interest. In Germany, endemic pathogens, such as hantavirus (with its reservoir in small rodents), tick-borne pathogens (Borrelia burgdorferi, tick-borne encephalitis virus), and certain food- and water-borne pathogens, are of concern. Mild winters favor ro- dent populations and may result in hantavirus epidemics in the subsequent summer period. Statistical analyses show a significant association between temperature and campylobacter incidence in Germany. An outbreak of rodent-borne leptospirosis among strawberry harvesters enhanced by heavy rainfalls illustrates how weather conditions may influence disease occurrence. Pathogens that are non-endemic in Germany but are imported by humans, vectors, and reservoir animals pose an additional risk to the population. Increasing temperatures improve the conditions for establishment of new vectors and for autochthonous transmission of some pathogens (e.g., chikungunya, dengue, West kungunya-, West-Nile-, Dengue-Fieber, Malaria und Leishmaniose zu nennen. Unter den derzeitigen klimatischen Verhältnissen sind in Deutschland für die meisten dieser Erreger noch keine autochthonen Erkrankungsfälle zu erwarten. Aufgrund des erwarteten Temperaturanstiegs und verbesserter Brutbedingungen für die Vektoren müssen wir jedoch auch in Deutschland in Zukunft mit Ausbrüchen durch einige dieser Erreger rechnen. Verstärkte Forschungs- und Public-Health-Aktivitäten im Bereich Klimawandel und Infektionskrankheiten sind erforderlich.

\section{Schlüsselwörter}

Klimawandel · Temperaturanstieg · Neue Infektionskrankheiten · Menschliche Gesundheit

Nile virus, malaria, or leishmaniasis). Climatic and ecologic conditions in Germany currently do not favor autochthonous outbreaks for most of these pathogens. However, if temperatures increase, as expected, such outbreaks will become more likely. Germany should enhance its research in public health activities in the field of climate change and infectious diseases.

\section{Keywords}

Climate change $\cdot$ Increasing temperature $\cdot$ Infectious diseases - Emerging diseases $\cdot \mathrm{Hu}-$ man health 


\begin{tabular}{|c|c|c|c|c|c|}
\hline Infektionserreger & Überträger/Vektor & Verbreitung & $\begin{array}{l}\text { Kompetente } \\
\text { Vektoren in } \\
\text { Deutschland }\end{array}$ & $\begin{array}{l}\text { Importierte Infek- } \\
\text { tionserreger }\end{array}$ & $\begin{array}{l}\text { Abschätzung des Risikos für } \\
\text { die Ausbreitung beziehungs- } \\
\text { weise einen Ausbruch }\end{array}$ \\
\hline $\begin{array}{l}\text { Frühsommer Meningo- } \\
\text { Enzephalitis-Virus* }^{*}\end{array}$ & $\begin{array}{l}\text { Zecken (Ixodes ssp, } \\
\text { I. ricinus) }\end{array}$ & $\begin{array}{l}\text { Mittel- Nordeuropa, } \\
\text { Russland, nördliches } \\
\text { Asien }\end{array}$ & Vorhanden & $\begin{array}{l}\text { Infizierte Haus- und } \\
\text { Wildtiere }\end{array}$ & Möglich \\
\hline Hantavirus & Nager & $\begin{array}{l}\text { Mittel- Nordeuropa, } \\
\text { Russland, Amerika, } \\
\text { Asien }\end{array}$ & Vorhanden & $\begin{array}{l}\text { Infizierte Haus- und } \\
\text { Wildtiere }\end{array}$ & Möglich \\
\hline Tollwut-Virus ${ }^{*}$ & Haus-, Wildtiere & $\begin{array}{l}\text { Europa, Asien, } \\
\text { Amerika }\end{array}$ & Vorhanden & $\begin{array}{l}\text { Infizierte Haus- und } \\
\text { Wildtiere }\end{array}$ & Gering \\
\hline Sandfliegenfieber-Virus & Sandfliegen & $\begin{array}{l}\text { Südeuropa, Mittel- } \\
\text { meerländer }\end{array}$ & $\begin{array}{l}\text { Lokal vorhanden, } \\
\text { Rheingraben }\end{array}$ & $\begin{array}{l}\text { Infizierte Personen, } \\
\text { infizierte Vögel }\end{array}$ & Möglich \\
\hline West-Nile-Virus & $\begin{array}{l}\text { Mücken (Culex u. } \\
\text { Aedes ssp.) }\end{array}$ & $\begin{array}{l}\text { Südfrankreich, } \\
\text { Balkan }\end{array}$ & Vorhanden & Infizierte Personen & Möglich \\
\hline $\begin{array}{l}\text { Lymphozytäres } \\
\text { Choriomeningitis-Virus }\end{array}$ & Nager, Hamster & Europa & Vorhanden & Infizierte Nager & Möglich \\
\hline $\begin{array}{l}\text { Krim Kongo } \\
\text { Hämorragisches Fieber }\end{array}$ & $\begin{array}{l}\text { Zecken (Hyalomma } \\
\text { ssp.) }\end{array}$ & $\begin{array}{l}\text { Afrika, Mittlerer } \\
\text { Osten, Balkan, Türkei }\end{array}$ & & Infizierte Personen & Gering \\
\hline Chikungunya-Virus & Mücken (Aedes ssp.) & $\begin{array}{l}\text { Afrika, Asien, } \\
\text { Oberitalien }\end{array}$ & Lokal vorhanden & Infizierte Personen & Möglich \\
\hline Dengue-Virus & $\begin{array}{l}\text { Mücken (Aedes ssp., } \\
\text { A. aegypti) }\end{array}$ & $\begin{array}{l}\text { Südamerika, Asien, } \\
\text { Afrika }\end{array}$ & Lokal vorhanden & $\begin{array}{l}\text { Infizierte Personen, } \\
\text { Warenimport }\end{array}$ & Möglich \\
\hline Gelbfieber-Virus $^{*}$ & Mücken (Aedes ssp.) & Afrika, Südamerika & Lokal vorhanden & $\begin{array}{l}\text { Warenimport, infi- } \\
\text { zierte Personen }\end{array}$ & Möglich \\
\hline $\begin{array}{l}\text { Japanisches Enzephalitis- } \\
\text { Virus }^{*}\end{array}$ & Mücken (Culex ssp.) & Asien & Lokal vorhanden & $\begin{array}{l}\text { Warenimport, infi- } \\
\text { zierte Personen }\end{array}$ & Gering \\
\hline Rift-Tal-Fieber-Virus & $\begin{array}{l}\text { Mücken (Culex u. } \\
\text { Aedes ssp.) }\end{array}$ & $\begin{array}{l}\text { Afrika, Mittlerer } \\
\text { Osten }\end{array}$ & Lokal vorhanden & $\begin{array}{l}\text { Warenimport, infi- } \\
\text { zierte Personen }\end{array}$ & Gering \\
\hline
\end{tabular}

lance, die eine detaillierte Erfassung der Ausbreitung der verschiedenen Vektoren zum Ziel hat, derzeit nicht durchgeführt wird. Diese fehlenden Informationen machen es daher auch sehr schwer, klare Aussagen über die zunehmende Ausbreitung und die daraus resultierenden Risiken zu treffen, zumal die Einflussfaktoren für eine Verbreitung der Vektoren bei Weitem noch nicht verstanden sind. Bekannt sind hingegen die klimatischen und Umweltparameter, die erfüllt sein müssen, damit sich der eine oder andere Vektor ansiedeln kann. Inwieweit sich diese Vektoren an die sich verändernde Bedingungen anpassen können, bleibt allerdings eine Frage, die derzeit nicht beantwortet werden kann.

\section{Einheimische vektorassoziierte Infektionen}

\section{Borrelia burgdorferi}

Borrelia burgdorferi ist der durch Zecken (überwiegend Ixodes ricinus) übertragene Erreger der Lyme-Borreliose. Sie ist in Deutschland und Europa weit ver- breitet. Die Infektionswahrscheinlichkeit beim Menschen wird bestimmt durch das Zeckenvorkommen, die Erregerprävalenz in den Zecken und Reservoirtieren und das Verhalten in Beruf und Freizeit. Es ist möglich, dass durch klimatische Veränderungen die Zeckendichte in Deutschland zunimmt und Menschen durch verändertes Freizeitverhalten bei länger andauernden Wärmeperioden stärker exponiert sind. Allerdings gibt es keinen einfachen Zusammenhang zwischen Temperatur und Borreliose-Inzidenz beim Menschen. Die geografische Verteilung und die Populationsdichte der Zecken hängt von weiteren ökologischen und klimatischen Faktoren wie Habitatstruktur (Vegetation et cetera), Populationsdichte der Reservoirtiere (zum Beispiel Nager) und Feuchtigkeit ab [3]. Warme Winter erleichtern das Überleben und die Vermehrung der Vektoren und begünstigen eine höhere Zeckendichte und -aktivität bereits im Frühjahr. Andererseits führen heiße trockene Sommer zu einer Reduktion der Zeckenpopulationen. Aufgrund der für Deutschland nur lückenhaft existierenden Daten zu den meisten der oben genannten Variablen ist es derzeit nicht möglich, zuverlässige Prognosen zur Auswirkung bestimmter klimatischer Veränderungen (Temperaturanstieg) auf die Borreliose-Inzidenz abzugeben.

Die Lyme-Borreliose ist derzeit nur in den östlichen Bundesländern meldepflichtig. Eine detaillierte Auswertung der Meldedaten ergab folgendes Bild. Im Zeitraum 2002 bis 2006 wurden insgesamt 23.119 Fälle mit klinischem Bild der Lyme-Borreliose (entsprechend Falldefinition) übermittelt, davon 20.787 Fälle als Erythema migrans [4]. Die Inzidenz stieg um $100 \%$, allerdings mit deutlichen regionalen Unterschieden. In allen Jahren lag der Erkrankungsgipfel zwischen Juni und September. In den Jahren 2005 und 2006 wurde im Vergleich zu den Vorjahren für einen größeren Anteil der Erkrankungsfälle ein Beginn in den Monaten September bis November übermittelt. In beiden Jahren begünstigten ein warmer Herbst und ein milder Winter eine verlängerte 
Zeckenaktivität [5]. In den Jahren 2007 und 2008 gingen in einigen Bundesländern die Fallzahlen wieder leicht zurück, allerdings lagen sie immer noch deutlich über dem Niveau von 2004.

Für die höhere Borreliose-Inzidenz der letzten Jahre gibt es verschiedene Erklärungsansätze. Eine tatsächliche Inzidenzzunahme, bedingt durch bessere Zeckenhabitate (zum Beispiel Erhöhung des Anteils von Laub- und Mischwäldern in einigen Regionen) und verändertes Freizeitverhalten (zum Beispiel mehr Aktivitäten im Freien), ist wahrscheinlich. Aber auch verstärkte diagnostische Aufmerksamkeit und verbessertes Meldeverhalten können eine Rolle spielen. Von einer Untererfassung der Erkrankungsfälle ist auszugehen. Bundesweite Surveillance beziehungsweise gezielte epidemiologische Studien zur Erfassung der Prävalenz und Inzidenz sind notwendig [6]. Eine Aufnahme der Lyme-Borreliose in die gesetzliche Meldepflicht ist zu erwägen.

\section{FSME-Virus (Frühsommer- Meningoenzephalitis)}

Die Frühsommer-Meningoenzephalitis (FSME) stellt derzeit neben der LymeBorreliose die bedeutendste durch Vektoren übertragene Infektionskrankheit in Europa und Deutschland dar. Das FSMEVirus gehört zu den Flaviviren. Die das Virus übertragenden Zecken kommen in vielen europäischen Ländern, in Russland und in Asien vor. Wesentliche Verbreitungsgebiete in Deutschland liegen in Baden-Württemberg und Bayern. Endemiegebiete finden sich außerdem im südlichen Hessen (Odenwald), im Landkreis Birkenfeld in Rheinland-Pfalz und in vereinzelten Landkreisen in Thüringen [7]. In den FSME-Endemiegebieten Deutschlands sind zirka 0,1-5\% der Zecken mit dem Virus infiziert. Die Krankheit tritt je nach Aktivität der Virus-tragenden Zecken (in Deutschland vor allem Ixodes ricinus) bevorzugt im Frühjahr und Sommer auf, häufig jedoch auch im Herbst. Bei warmer Witterung kommt es vereinzelt auch zu Infektionen im Winter. Obwohl ein effizienter Impfstoff zur Verfügung steht, gab es in den Jahren 2005 bis 2008 in Deutschland eine nicht geringe Anzahl von Erkrankungsmeldungen (• Abb. 2). Gerade für die durch Zecken

FSME-Fälle mit Referenzdefinition

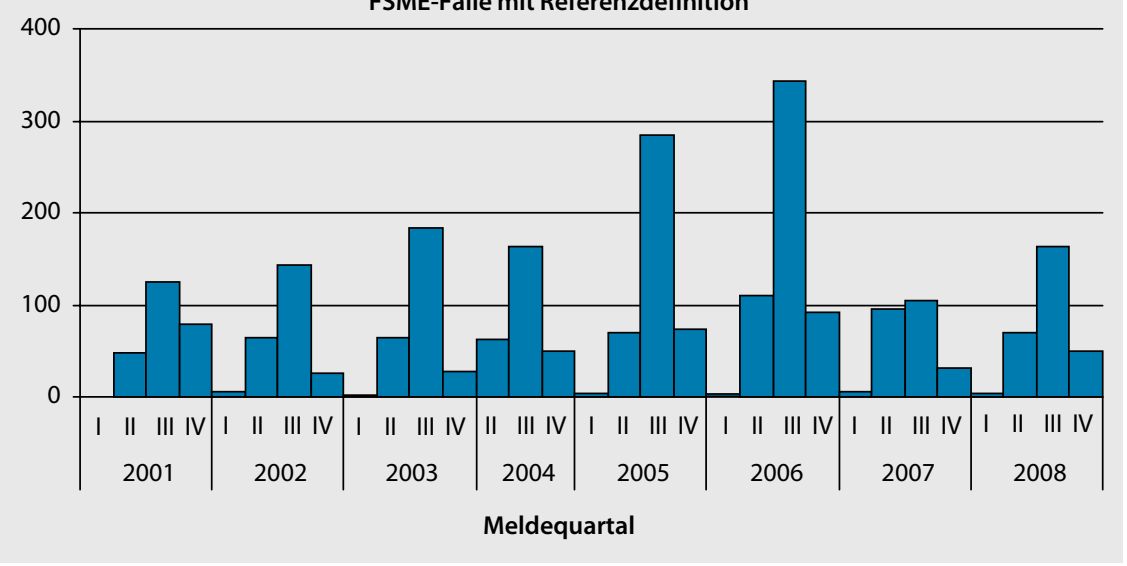

Abb. $2 \Delta$ FSME-Erkrankungen nach Meldequartal (übermittelt an das RKI nach IfSG), Deutschland, 2001-2008

übertragenen Infektionskrankheiten wie Borreliose und FSME ist eine durch steigende Temperaturen bedingte Zunahme möglich. So haben neu aufgetretene FSME-Fälle zum Beispiel in Nordhessen in den letzten Jahren zu einer Ausweitung der deklarierten Endemiegebiete geführt [8]. Die Ursachen für diese Ausbreitung sind allerdings unklar. Insgesamt sind die FSME-Endemiegebiete weiterhin auf den südlichen Teil Deutschlands beschränkt. Die Anzahl der gemeldeten Fälle hat von 2001 bis 2006 deutlich zugenommen, war allerdings im Jahr 2007 wieder geringer, was auf den verregneten Sommer mit verminderten Feizeitaktivitäten zurückgeführt wurde. Auch eine Zunahme der Durchimpfungsraten der Bevölkerung in den Endemiegebieten hat wahrscheinlich zu den relativ stabilen FSME-Inzidenzen in 2007 und 2008 beigetragen.

\section{Hantaviren}

Die in Mitteleuropa verbreiteten Typen von Hantaviren verursachen eine Erkrankung, die als hämorrhagisches Fieber mit renalem Syndrom (HFRS) oder Nephropathia endemica bezeichnet wird. In Deutschland spielen vor allem das Puumala-Virus (Reservoir: Rötelmaus) und im Nordosten das Dobrava-Virus (Reservoir: Brandmaus) eine Rolle. Die Viren werden von persistent und inapparent infizierten Nagetieren über Speichel, Urin und Kot ausgeschieden. Der Erreger kann auch in der Umwelt über längere Zeiträume infektiös bleiben. Die Übertragung auf den Menschen erfolgt zumeist durch Inhalation virushaltiger Aerosole. Die Infektionshäufigkeit beim Menschen wird stark beeinflusst durch die Dichte der Mäusepopulationen, die mehrjährigen zyklischen Schwankungen unterliegt. Klimatische Bedingungen (zum Beispiel besseres Nahrungsangebot und Überlebensbedingungen für Mäuse in milden Wintern) begünstigen die Vermehrung der Reservoirtiere. Besonders hohe Erkrankungsinzidenzen werden in Deutschland in einigen Endemiegebieten (Schwäbische Alb in Baden-Württemberg, Bayerischer Wald, Nordbayern/Südhessen, Eifel in Nordrhein-Westfalen und andere) beobachtet.

Seit Inkrafttreten des Infektionsschutzgesetzes (IfSG) im Jahr 2001 ist der Labornachweis einer akuten Hantavirus-Infektion meldepflichtig. Die Analyse der Meldedaten lässt aufschlussreiche epidemiologische Trends erkennen. Von 2001 bis 2008 wurden insgesamt 3248 laborbestätigte Hantavirus-Erkrankungen an das Robert Koch-Institut (RKI) übermittelt (- Abb. 3). Die Inzidenz wies in der Regel einen Gipfel in den Sommermonaten Mai bis August auf, variierte aber deutlich zwischen verschiedenen Jahren. Im Jahr 2007 gab es einen neuen Höchststand mit 1687 Erkrankungsfällen (65\% davon in Baden-Württemberg) (• Abb.4). Dies waren fast viermal so viele Fälle wie im Jahr $2005(n=448)$, dem Jahr mit der zweithöchsten Inzidenz. In den übrigen Jahren vor 2006 bewegten sich die jährlichen Fallzahlen zwischen 72 (2006) und 242 (2004). Charakteristisch für das Jahr 2007 war ein früher Anstieg der Inzidenz bereits im April. Erste Fall-Kontroll-Studien beim Menschen in den Jahren mit hoher Inzidenz (2005: bundesweit, 2007: 
Hantavirus-Fälle mit Referenzdefinition

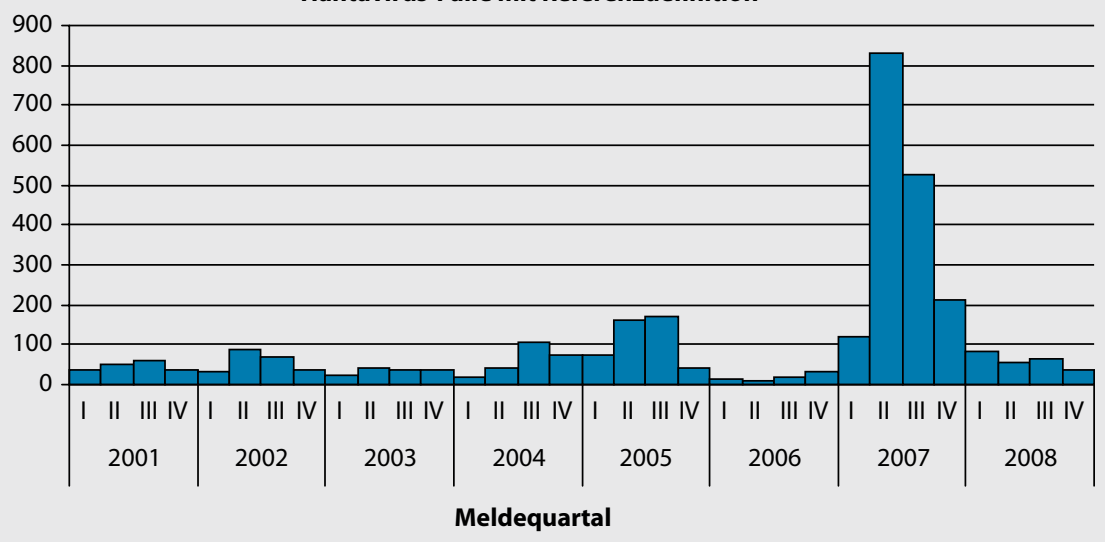

Abb. $3 \Delta$ Hantavirus-Erkrankungen nach Meldequartal (übermittelt an das RKI nach IfSG), Deutschland, 2001-2008

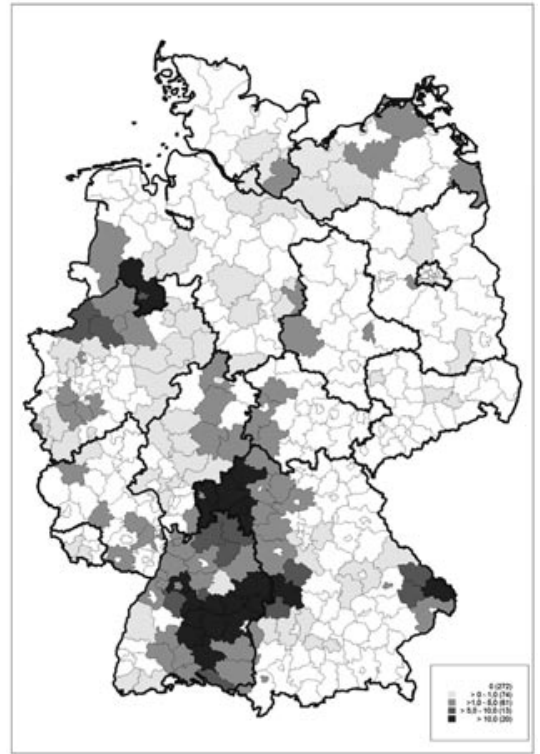

Abb. $4 \Delta$ Hantavirus-Erkrankungen pro 100.000 Einwohner nach Kreis, Deutschland, $2007(n=1687)$

Baden-Württemberg) deckten wichtige Risikofaktoren auf (zum Beispiel Tätigkeit in der Forstwirtschaft und im Bauwesen oder die freizeitbedingte Nutzung von Waldhütten in Endemiegebieten) [9].

Es gibt deutliche Hinweise, dass aufgrund des sehr milden Winters 2007 (fehlende oder nur kurzfristig vorhandene Schneedecke zum Beispiel im Endemiegebiet Schwäbische Alb) und eines reichhaltigen Nahrungsangebotes (Bucheckernmast) die Mäusepopulationen ungewöhnlich stark zunahmen [9][10] Der ursächliche Einfluss witterungsbedingter Faktoren auf die Rekordinzidenz im Jahr 2007 lässt sich nicht abschließend beurtei- len. Für die entsprechenden Modellrechnungen sind neben den Klimadaten und den im Rahmen der Meldepflicht gewonnenen Inzidenzdaten bessere und umfassendere Daten zu den Mäusereservoirs notwendig (zum Beispiel Determinanten der Populationsdichte und -dynamik und der Hantavirus-Prävalenz).

Die Leptospirose (M. Weil, Feldfieber, Bataviafieber, Erbsenpflückerkrankheit, Reisfeldfieber) ist eine durch Spirochäten des Genus Leptospira hervorgerufene Zoonose, die vor allem in den Subtropen und gemäßigten Klimaten weltweit verbreitet ist. In Deutschland wurden seit 1990 um die 50 Erkrankungen pro Jahr (überwiegend Einzelfälle) gemeldet. Die Krankheit wird vorwiegend durch kontaminierten Urin von befallenen Tieren verbreitet. Der Mensch nimmt den Erreger durch Kontakt mit verseuchtem Boden, Schlamm oder Wasser über Hautläsionen, Schleimhäute oder die Konjunktiven auf [11]. Schwere Verläufe führen in $8 \%$ bis $22 \%$ der Patienten zu einem letalen Verlauf [12]. In Deutschland hat es im Juli 2007 erstmals seit 40 Jahren einen Ausbruch mit mehr als 15 Erkrankten gegeben [13]. Bedingt durch regionale Starkniederschläge, eine mittlere Lufttemperatur über $18^{\circ} \mathrm{C}$ und eine hohe lokale Populationsdichte von Wirtstieren (in diesem Fall Feldmäuse) kam es zu einem Ausbruch von 28 Erkrankungen durch den Subtyp Leptospirosa grippothyphosa bei Erdbeerpflückern [14]. Die für den Ausbruch prädisponierenden Faktoren Star-

\section{Leptospiren}

kniederschläge mit lokalen Überschwemmungen, Anstieg der mittleren Lufttemperatur über $18^{\circ} \mathrm{C}$ im Sommer und ausbleibende Rückführung der Populationsdichte bei den Wirtstieren durch Frost in den Wintermonaten werden durch die für Deutschland prognostizierten Klimaänderungen begünstigt.

\section{Francisella tularensis}

Die Tularämie (Hasenpest, Deer-fly Fever, Meat-Cutter's-Disease) wird durch das Bakterium Francisella tularensis, einen extrem umweltstabilen Erreger hervorgerufen. In Europa ist die Subspezies F. tularensis holarctica weit verbreitet. Nur die britischen Inseln und Portugal sind frei von Tularämie. Als Reservoir fungieren Wildtiere, vor allem Hasen und $\mathrm{Na}$ getiere [15].

Das Vorkommen von Tularämie beim Menschen ist als zoonotische Erkrankung eng mit den Bedingungen für die Wirtspopulation und die Vektoren verbunden. So sind die in Deutschland aufgetretenen Fälle und insbesondere die Erkrankungscluster (zuletzt im Jahr 2006 mit zehn Erkrankten) überwiegend auf einen direkten Kontakt mit Hasen zum Beispiel beim "Abbalgen" der Tiere zurückzuführen [16]. Daneben werden aber auch Vektoren, wie zum Beispiel Zecken, beschrieben [17]. Ein Klimawandel könnte mit direkten Auswirkungen auf die Nager- beziehungsweise Hasenpopulation oder auf Vektoren wie Zecken [18] ein vermehrtes Auftreten der in Deutschland bisher extrem selten auftretenden Erkrankung (1974 bis 2005 im Durchschnitt drei gemeldete Erkrankungen pro Jahr) begünstigen. Beispiele aus anderen europäischen Ländern zeigen, dass nach einer starken Zunahme der Nagerpopulation, wie im Kosovo 1999 und 2000 als Kriegsfolge wegen der nicht abgeernteten Felder und der zerstörten Infrastruktur, die Tularämie sich unter den Nagern epidemieartig verbreitete [19]. Da der Erreger wegen seiner extremen Tenazität auch in Tierkadavern über Wochen vermehrungsfähig bleibt, kam es in der Folge auch zum Überspringen der Erkrankung auf den Menschen mit einem Ausbruch von über 300 bestätigten Fällen. Es ist nicht ausgeschlossen, dass eine klimatische Veränderung hier einen vergleichbaren Effekt 


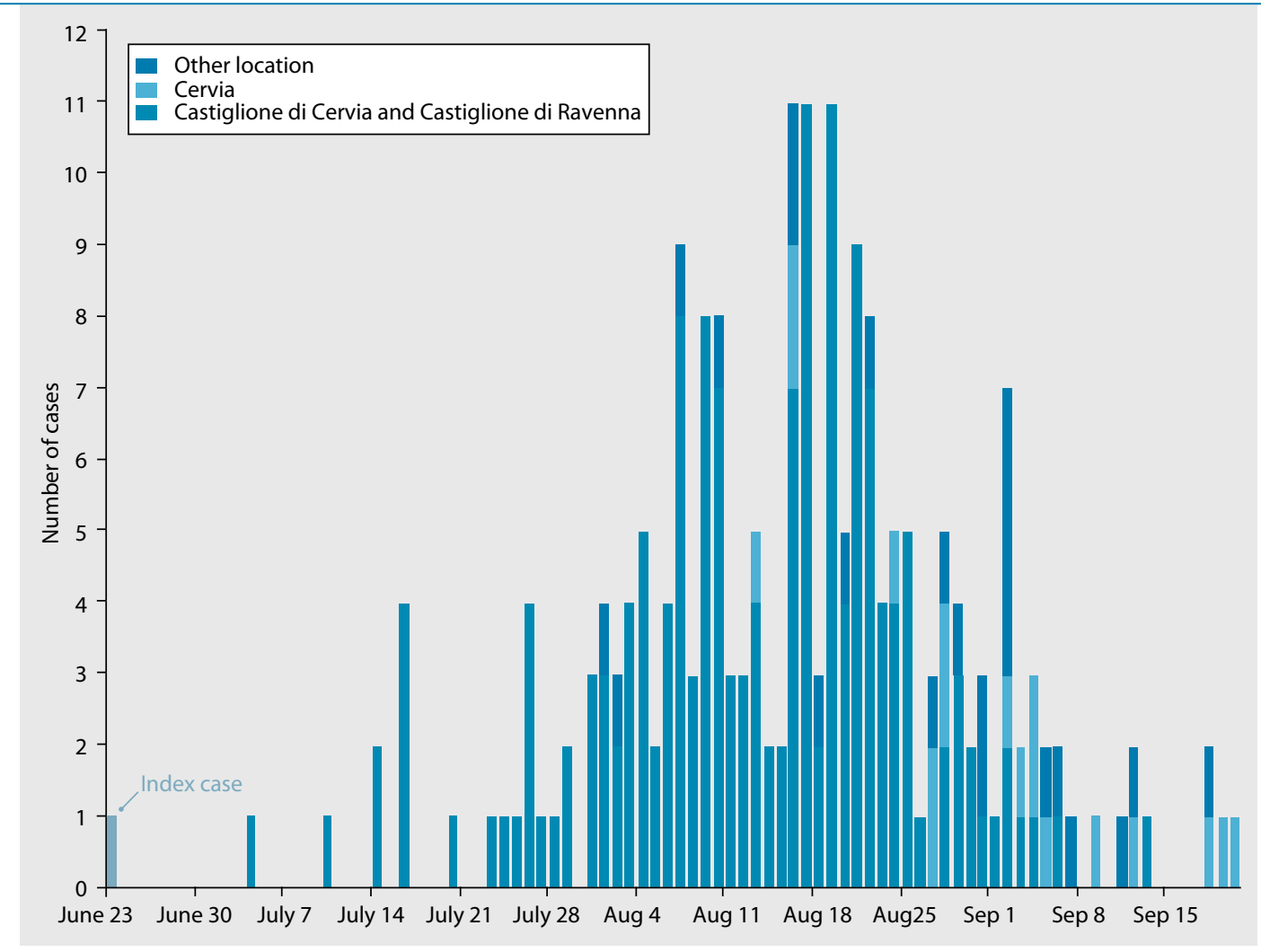

Abb. 5 - Chikungunyafieber-Ausbruch, Norditalien, Sommer 2007. (Quelle: [35])

auf die Hasen- oder Nagerpopulation in Deutschland haben könnte.

\section{Importierte vektorassoziierte Infektionen}

Bei den importierten Infektionen muss zwischen zwei grundsätzlich verschiedenen Möglichkeiten für den Import von mit Infektionserregern infizierten Vektoren unterschieden werden. Mittels schneller Flugverbindungen können Reisende die in den Tropen erworbenen Infektionskrankheiten einschleppen. Andererseits können Warenlieferungen, die in Schiffen oder Flugzeugen aus Endemiegebieten eintreffen, neue Vektoren (Nager, Mücken) und/oder neue Infektionserreger importieren, die sich in Deutschland oder Europa weiter verbreiten können. Ob eine solche Weiterverbreitung erfolgt, hängt außer von den klimatischen Faktoren vom Vorhandensein geeigneter/ kompetenter Vektoren in ausreichender Dichte ab. Dass diese Bedingungen für eine autochthone Übertragung unter bestimmten Voraussetzungen gegeben sind, hat sich in eindrucksvoller Weise im Sommer 2007 in Oberitalien in der Region Emilia Romagna gezeigt. Die Einreise einer mit dem Chikungunya-Virus infizierten Person aus
Indien führte zu einem inzwischen epidemiologisch und virologisch gut dokumentierten Ausbruch (• Abb. 5). Dieser wurde durch dort in großer Dichte vorkommende Aedes-Mücken ermöglicht. Insgesamt erkrankten 205 Personen und ein 83Jähriger, der an Vorerkrankungen litt, verstarb [20][21].

\section{Malaria-Plasmodien}

Nach WHO-Schätzungen leben etwa 40\% der Weltbevölkerung in Malariarisikogebieten. Jedes Jahr erkranken mehr als 500 Millionen Menschen an Malaria, und mehr als eine Million Menschen sterben daran, überwiegend Kinder und schwangere Frauen in Sub-Sahara-Afrika. Die geografische Verbreitung der Malaria hat sich im 20. Jahrhundert trotz der dokumentierten globalen Erwärmung vor allem durch den Rückgang in gemäßigten und subtropischen Regionen reduziert. Auch aus Europa ist die Malaria verschwunden. Hierfür waren neben ökologischen Faktoren (Verschlechterung der Brutbedingungen für Vektoren zum Beispiel durch Trockenlegung von Sümpfen, Mückenbekämpfung und andere) vor allem sozioökonomische Faktoren (medizinische Versorgung und andere) von entscheidender Bedeutung.
In vielen tropischen Regionen ist jedoch gegen Ende des 20. Jahrhunderts die Malariainzidenz deutlich gestiegen. Überdies wurde in einigen Regionen (zum Beispiel Ostafrika) über eine zunehmende Ausbreitung in größere Höhenlagen berichtet, was zum Teil durch den Einfluss von Klimaphänomen erklärt wird [22].

Anopheles-Mücken, die Malaria-Erreger übertragen könnten, sind in Europa und auch in Deutschland weiterhin vorhanden. In Europa existieren etwa 18 verschiedene Anopheles-Arten - am wichtigsten sind diejenigen aus dem Anopheles-maculipennis-Komplex [23]. Zur Vektorkompetenz der in Deutschland nachgewiesenen Anopheles-Arten ist wenig bekannt, und das heutige Risiko einer Malaria-Übertragung durch früher effiziente Anopheles-Mücken ist schwer einzuschätzen. Prinzipiell bedeutet aber eine Erwärmung, dass effizientere Malaria-Vektoren nach Europa vordringen können und sich die Entwicklungsbedingungen für die Parasiten in den Vektoren verbessern.

Jedes Jahr werden durch Reiserückkehrer Malaria-Infektionen nach Deutschland eingeschleppt. Seit 2001 sind in Deutschland entsprechend der Meldepflicht nach dem IfSG jährlich zwischen 500 und 1000 


\section{Originalien und Übersichtsarbeiten}

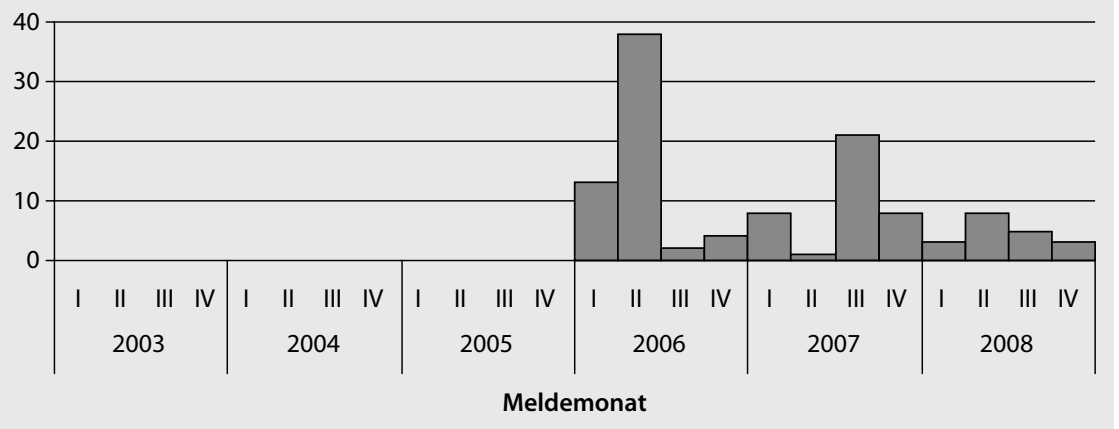

Abb. $6 \Delta$ Importierte Chikungunyavirus-Erkrankungen nach Meldequartal, Deutschland, 2006-2008

importierte Malariafälle gemeldet worden mit kontinuierlichem Rückgang der Inzidenz seit 2001 [24]. Die Malaria-Patienten in Deutschland können prinzipiell, sofern sie Malaria-Erreger in übertragungsfähigen Entwicklungsstadien (Gametozyten) im Blut tragen, als Infektionsquelle für einheimische vektorkompetente Anopheles-Mücken dienen. Einzelfälle von autochthoner Malaria wurden dementsprechend in Deutschland beschrieben, so etwa 1997 bei zwei Patienten in einem Duisburger Krankenhaus, in dem gleichzeitig ein Malaria-Patient stationär behandelt wurde [25]. Bei zunehmend stärkerer Erwärmung werden zunächst in Südeuropa und in Deutschland die prinzipiellen Voraussetzungen für eine Malaria-Übertragung günstiger werden. Mit sporadischen Fällen autochthoner Übertragung ist dann zu rechnen. Größere Ausbrüche von autochthoner Malaria oder gar eine längerfristige Etablierung des Malaria-Erregers in Deutschland sind angesichts der hohen medizinischen Standards (Früherkennung und effiziente Therapie bei Malaria-Erkrankten und damit Verhinderung von übertragungsfähigen Erregerreservoirs) äußerst unwahrscheinlich.

\section{Leishmanien}

Leishmanien-Spezies verursachen Krankheitsbilder, die sich in die drei Gruppen kutane, mukokutane oder viszerale Leishmaniose unterteilen lassen. Die Protozoen werden durch Phlebotomen (Sandmücken) übertragen. Abhängig von der Leishmanien-Spezies sind verschiedene Säugetiere als Reservoir relevant (vor allem Hunde, aber auch Nagetiere, Katzen und andere). Leishmanien kommen in vielen tropischen und subtropischen Regionen der Erde vor. Im Mittelmeerraum und Nahen Osten ist Leishmania infantumzum Teil endemisch verbreitet. Bei einer Infektion haben vor allem Kinder und Personen mit Immunsuppression (zum Beispiel HIV-Infektion, Drogenabusus) ein höheres Risiko einer klinisch manifesten viszeralen Leishmaniose. In manchen Gegenden Südeuropas wurden bei Hunden Infektionsprävalenzen (Serologie, PCR) von $20 \%$ und mehr gefunden [26]. Mit Leishmanien infizierte Hunde insbesondere aus den Endemiegebieten des Mittelmeerraumes werden auch nach Deutschland verbracht. Entscheidend für die Etablierung des Lebenszyklus von Leishmanien ist das Vorkommen geeigneter Vektoren.

Bereits gegenwärtig ist eine große Anzahl von Personen, die aus Deutschland in Endemiegebiete reisen, potenziell gegenüber Leishmanien exponiert. So haben jedes Jahr etwa 18 Millionen Reisen (durchschnittliche Dauer zwei Wochen) aus Deutschland den europäischen Mittelmeerraum zum Ziel. Im Zeitraum von 2000 bis 2007 wurden von der Beratungsund Dokumentationsstelle für Leishmaniosen am Institut für Tropenmedizin Berlin bundesweit insgesamt 56 Leishmaniosen (29 kutane/mukokutane L., 27 viszerale L.) erfasst, die aus europäischen Mittelmeerländern importiert worden waren [27]. Aufgrund der Erfassung auf freiwilliger Basis ist von einer gewissen Dunkelziffer auszugehen. Dennoch ist insgesamt das Risiko gering, bei einer Reise in die Endemieregionen eine symptomatische Leishmanien-Infektion zu erwerben.

Bisher wurden in Süddeutschland zwei Sandmückenarten nachgewiesen, die als potenziell geeignete Vektoren angesehen werden. Während Phlebotomus perniciosus Leishmanien übertragen kann, ist für die in Süddeutschland entdeckte Spezies Phlebotomus mascittii bisher kei- ne Vektorkompetenz belegt. Die Ausbreitung von Phlebotomenarten ist in der Regel durch die $10^{\circ} \mathrm{C}$-Jahresisotherme begrenzt, die in den 1990er-Jahren längs des Rheins bis auf die Höhe von Köln reichte. Durch die globale Erwärmung wird diese sich weiter nach Norden verschieben.

Unter den derzeitigen Bedingungen ist das Risiko von autochthonen Infektionen bei Menschen in Deutschland sehr gering. Zwar kam es in den letzten Jahren vereinzelt zu wahrscheinlich autochthon übertragenen Leishmaniose-Erkrankungen bei einem Kleinkind, das sich nie in Endemiegebieten aufgehalten hatte [28], bei Hunden und bei einem Pferd [29]. Die Wahrscheinlichkeit, dass autochthone Erkrankungsfälle beim Menschen in nennenswerter Anzahl über einen längeren Zeitraum unerkannt bleiben, erscheint angesichts der differenzialdiagnostischen Standards in Deutschland gering.

Im Falle klimatischer Veränderungen im Sinne einer Steigerung der mittleren Temperaturen (Verschiebung der $10^{\circ} \mathrm{C}$ Jahresisotherme) muss jedoch in bestimmten Regionen Deutschlands damit gerechnet werden, dass sich geeignete Vektoren für die Leishmaniose etablieren beziehungsweise ausbreiten und dass die Infektion insbesondere bei Hunden endemisch werden kann. Dann sind auch autochthone Infektionen beim Menschen ein realistisches Szenario.

Es wäre wichtig, frühzeitig eine umfassend und gut funktionierende Surveillance für den Bereich der Vektoren (systematische entomologische Untersuchungen), der Hunde (Prävalenzstudien bei Hunden) und der Menschen (Früherkennung von autochthonen Fällen) zu etablieren. Um eine lokale Ausbreitung in Deutschland frühzeitig und möglichst umfassend erkennen zu können, wäre eine Aufnahme von menschlichen Leishmaniose-Infektionen in die Liste der gemäß IfSG meldepflichtigen Erregernachweise ( $\$ 7$ IfSG) zu erwägen. Dies würde die Daten der oben genannten Beratungs- und Dokumentationsstelle für Leishmaniosen sinnvoll ergänzen und einen besseren Überblick über die Situation bei den importierten Leishmaniosen ermöglichen. Vordringlich und auch für die Überwachung anderer Erreger nützlich - ist jedoch eine verbesserte Datenlage zum Auftreten kompe- 
Hier steht eine Anzeige.

第 Springer 
tenter Überträgermücken sowie zum Auftreten von vektorübertragenen Erkrankungen bei tierischen Wirtspopulationen. Die Einfuhr von Hunden und Katzen aus Südeuropa sollte begrenzt werden.

\section{Dengue-Virus}

Das Dengue-Virus gehört wie das Gelbfieber-Virus zur Familie der Flaviviren und wird vor allem durch Mücken der Gattung Aedes [3o] übertragen. Denguefieber zählt nach Einschätzungen der WHO zu den größten gesundheitlichen Bedrohungen weltweit. Dies wird einerseits durch die weltumspannende Ausbreitung in allen tropischen Gebieten, andererseits durch das Vorkommen von vier verschiedenen Serotypen (1-4) gefördert. Hierdurch ist es möglich, sich nacheinander mit verschiedenen Serotypen zu infizieren, wobei die zweite Infektion mit einem anderen Serotyp einen schwereren Verlauf nehmen kann. Abhängig von der Schwere der Infektion kann es neben Fieber zu hämorrhagischen Verläufen und auch zum Schocksyndrom mit häufig tödlichem Ausgang - kommen [31][32]. Ungeachtet der Tatsache dass jährlich wahrscheinlich mindestens 500 Dengue-Virus-Infektionen nach Deutschland importiert werden, ist die Wahrscheinlichkeit einer Weiterverbreitung durch einheimische Mücken eher gering. Auch wenn diese Infektionen zum Teil zu schweren klinischen Verläufen führen, dauert die Virämie nur wenige Tage und die nachgewiesenen Virustiter sind gering, was eine effiziente Übertragung und Ausbreitung erheblich erschwert. Außerdem sind die Virus-übertragenden Mücken in Deutschland bisher nicht etabliert [33].

Erste größere wissenschaftliche Feldstudien mit einem Dengue-Impfstoff laufen derzeit in Südostasien an. Bis zur Marktreife werden jedoch voraussichtlich noch einige Jahre vergehen.

\section{Gelbfieber-Virus}

Gelbfieber gehört wie das Dengue-Virus in die Familie der Flaviviren und ist nur in Afrika und Südamerika verbreitet, wo es durch Mücken übertragen wird. Mit jährlich geschätzten 200.000 Infektionen und 30.00o Todesfällen stellt das Gelbfieber nach wie vor eine ernste Bedrohung für die in diesen Gebieten lebende Bevölkerung dar. Trotz eines sehr effizienten Impfstoffes kommt es aufgrund der unzureichenden Durchimpfung der Bevölkerung in Afrika und Südamerika immer wieder zu Ausbrüchen und Todesfällen. Die starke Bevölkerungszunahme bei fehlendem Impfschutz stellt ein erhebliches Risiko für wiederkehrende Ausbrüche in den Ballungsgebieten beider Kontinente dar. So kam es im Frühjahr 2008 erstmals seit 70 Jahren zu einer Gelbfieberausbreitung in urbanen Randgebieten in Paraguay, was belegt, dass in den Dschungelgebieten der Region nach wie vor die Infektionserreger verbreitet sind. Gelegentlich erkranken ungeimpfte Reisende, die sich in den endemischen Gebieten aufhalten, mit zum Teil dramatischem Ausgang. So sind in den vergangenen zehn Jahren drei nach Europa importierte Fälle von Gelbfieber bekannt geworden. Alle drei Patienten sind an der Infektion verstorben. Das Risiko einer Einschleppung und autochthonen Verbreitung ist aufgrund des sehr akuten Krankheitsverlaufs sehr gering, zumal die intensivmedizinische Behandlung dieser Patienten einer Weiterverbreitung der Infektion durch Überträgermücken sicherlich entgegensteht. Anders sieht es hier mit dem Import über Waren aus. Die Einschleppung von potenziellen Aedes-albopictus-Vektoren durch Autoreifen aus Südamerika in die USA, die zu einem Gelbfieber- oder Dengue-Ausbruch führen könnte, ist gut belegt [34].

\section{Chikungunya-Virus}

Die in Afrika und Asien vorkommenden Chikungunya- (CHIK-)Infektionen haben seit $2005 \mathrm{zu}$ verschiedenen Ausbrüchen mit weit über 10o.ooo Erkrankten auf den Inseln des Indischen Ozeans (den Komoren, La Réunion, Madagaskar, Malediven) geführt, bevor weitere Ausbrüche in Indien, Sri Lanka und Singapur folgten. Die durch Aedes-Mücken übertragenen CHIK-Viren trafen hier auf eine weitestgehend naive Bevölkerung, da Ausbrüche in dieser Region lange Zeit nicht auftraten. Bei der Untersuchung der hohen Zahlen an Erkrankten in Indien hat sich herausgestellt, dass es bei dieser ansonsten nicht letalen Erkrankung offenbar doch zu einzelnen Todesfällen bei älteren Personen und solchen mit Vorerkrankungen kommt [35]. Durch die zahlreichen Urlauber, die in diese Region reisen, kam es zwangsläufig auch zu Importen von Infektionen bei Reiserück- kehrern; allein in Frankreich wurden zirka 164 Fälle erfasst [20]. Auch wenn sich die Befürchtungen, dass es hierbei, ausgehend von infizierten Reiserückkehrern, auch zur autochthonen Übertragung durch AedesMücken kommt, für Frankreich nicht bewahrheitet hat, so kam es doch in Italien zu einem CHIK-Ausbruch durch einen einreisenden infizierten Inder (vergleiche oben). Dies hat deutlich gezeigt, dass eine Einschleppung und Ausbreitung von CHIK-Infektionen bei geeigneten Voraussetzungen nicht nur möglich ist, sondern ein ernst zu nehmendes Szenario darstellt. Ob und gegebenenfalls wie sich die CHIKInfektion in Italien weiter etablieren wird, kann derzeit noch nicht abschließend gesagt werden. Im Jahr 2008 gab es in Italien keine weiteren Ausbrüche (• Abb. 5).

Auch nach Deutschland wurden in den letzten Jahren CHIK-Infektionen eingeschleppt (2006: 53 nach IfSG gemeldete Fälle, 2007: 32, 2008: 17) (• Abb. 6). Es ist von einer Untererfassung auszugehen, da bei mildem klinischem Verlauf häufig eine spezifische Diagnostik unterbleibt. Die relativ hohe Fallzahl in 2006 spiegelt die internationale Situation mit großen Ausbrüchen auf einigen Inseln des Indischen Ozeans und dem Indischen Subkontinent wider.

\section{West-Nile-Virus}

Das durch Culex-Mücken übertragene West-Nile-Virus (WNV) ist in weiten Teilen Afrikas und dem Vorderen Orient verbreitet. Verwandte Viren sind auch von Asien bis Australien beheimatet. Hauptwirte sind infizierte Vögel, die die Infektion über Mücken gelegentlich auch auf den Menschen übertragen. Die Bedeutung des West-Nile-Virus hat seit der Einschleppung des Virus aus Israel nach New York im Jahre 1999 erhebliche Aufmerksamkeit erlangt. Die anschließende Ausbreitung über den gesamten nordamerikanischen Kontinent, mit steigenden Zahlen an Infektionen und auch Todesfällen, zeigte auf eindruckvolle Weise, welche Folgen sich aus der Einschleppung von bisher unbekannten Infektionserregern in neue Ausbreitungsgebiete ergeben können. Die dadurch entstandenen Konsequenzen für die Bevölkerung und das Gesundheitssystem sind enorm und finanziell nicht zu beziffern. Auch wenn die Ausbreitung landesweit als abgeschlossen betrachtet werden kann, werden 
lokale Ausbrüche, verbunden mit gehäuften Erkrankungen und Todesfällen, das Gesundheitsgeschehen in Nordamerika auch weiterhin belasten. Zahlreiche Studien zum Vorkommen und zur Ausbreitung der WNV in Deutschland und Europa haben deutlich gezeigt, dass ein serologischer Nachweis in einheimischen Vögeln und Zugvögeln bei zirka $5 \%$ positiv ist [20][36]. Der Nachweis von infektiösem WNV gelang bisher in Deutschland nicht und auch in anderen europäischen Ländern nur sehr vereinzelt. Fälle von in Europa an WNV erkrankten Personen sind nach wie vor äußerst selten und werden bei Weitem von der Anzahl an Personen übertroffen, die sich auf einer Urlaubreise in den USA mit dem WNV infiziert haben. Allerdings ist es in den letzten Jahren in einzelnen europäischen Ländern zu sporadischen WNV-Erkrankungsfällen beziehungsweise kleineren Ausbrüchen gekommen (zum Beispiel Rumänien, Ungarn, Italien) [37].

Das Risiko für eine Einschleppung der WNV nach Deutschland über Zugvögel besteht schon seit langer Zeit. Ob die äuBerst kurze Virämie und/oder eine nur unzureichende Mückenpopulation bisher eine Etablierung in Deutschland verhindert haben, kann derzeit nicht sicher beurteilt werden. $\mathrm{Ob}$ und wie sich die Voraussetzungen bei sich verändernden Klimabedingungen entwickeln werden, ist ebenfalls offen. Die derzeit stabilen Endemiegebiete für WNV in der südfranzösischen Camargue, wo trotz intensiver Suche bisher keine Fälle bei Menschen gefunden wurden, lassen hoffen, dass sich die Voraussetzungen für eine Verbreitung in Europa grundsätzlich von denen in den USA unterscheiden.

\section{Pappataci-Virus}

Das durch Bunyaviren hervorgerufen Pappataci-Fieber ist im gesamten Mittelmeerraum verbreitet und verursacht fieberhafte Erkrankungen bei Einheimischen und Touristen. Da sich die Sandfliegen, die als Überträgervektoren fungieren, auch bereits im Oberrheingraben angesiedelt haben, wäre eine Einschleppung von Bunyaviren unter geeigneten Voraussetzungen durchaus möglich und hätte dann auch entsprechende Erkrankungen zur Folge. Da die Erkrankungen im Allgemeinen nicht tödlich verlaufen, ergeben sich im Falle einer
Einschleppung im Wesentlichen gesundheitliche Beeinträchtigungen für die betroffene Bevölkerung. Eine Risikoabschätzung bezüglich einer Einschleppung und Etablierung des Pappataci-Fiebers ist aufgrund der unzureichenden Datenlage extrem schwierig, zumal nur wenige Ergebnisse zu den endemischen Regionen in Mittelmeer vorliegen.

Für alle potenziell neuen Infektionserreger ergeben sich neben den gesundheitlichen Beeinträchtigungen direkte Konsequenzen für das Blut- und Plasmaspendewesen wie auch für Organtransplantationen. Um eine mögliche Übertragungen auf diesem Wege zu verhindern, ist die Einführung entsprechender diagnostischer Maßnahmen unbedingt erforderlich. Da derzeit für die meisten dieser Infektionserreger keine geeigneten kommerziellen diagnostischen Nachweissysteme angeboten werden, würden sich neben den Kosten hier zusätzliche diagnostische Probleme ergeben.

\section{Gastrointestinale Infektionskrankheiten}

\section{Durch Lebensmittel übertragene bakterielle Infektionen}

Lebensmittelbedingte Infektionen durch Salmonellen, Campylobacter und andere enterale Erreger zählen zu den häufigsten Infektionskrankheiten. In Deutschland wurden im Jahr 2007 55.400 Salmonellen-Erkrankungen und 66.107 Campylobacter-Erkrankungen an das RKI übermittelt. Im Vergleich zum Jahr 2006 entsprach dies einer Zunahme um 5\% bei Salmonellen und um 27\% bei Campylobacter [38]. Beide Erkrankungen weisen einen ausgeprägten saisonalen Trend auf mit deutlich erhöhter Inzidenz in den Sommermonaten. Dies gilt ebenfalls - wenn auch weniger ausgeprägt - für Infektionen mit enterohämorrhagischen $E$. coli (EHEC) und anderen E. coli. Einige bakterielle Enteritis-Erreger, wie zum Beispiel Salmonellen, vermehren sich bei hohen Temperaturen in Lebensmitteln und Futtermitteln wesentlich besser. Dies erklärt neben anderen Faktoren, warum einige Studien einen signifikanten Zusammenhang zwischen Außentemperatur und Salmonellose-Inzidenz beim Menschen feststellten [39]. Hinzu kommt, dass höhere

\section{Übersicht 1}

Mögliche Auswirkungen des

Klimawandels auf nicht-

infektiöse Krankheiten

- Physische und psychische Traumen durch Extremwetterereignisse (Hitzewellen, Überschwemmungen, Stürme et cetera)

- Herz-Kreislauf-Erkrankungen

- Atemwegserkrankungen

- Allergien

Hauterkrankungen

Temperaturen beziehungsweise Wärmeperioden in der Regel auch zu Veränderungen im Ernährungsverhalten der Menschen führen wie zu häufigerem Verzehr von Risikoprodukten (zum Beispiel Grillfleisch, Speiseeis, Frischeiprodukte).

Eine direkte Vermehrung von Campylobacter in Lebensmitteln ist unwahrscheinlich. Allerdings sind nach ausgeprägten Wärmeperioden erhöhte Campylobacter-Prävalenzen in Geflügelfleisch beschrieben worden. Ebenso wurde ein Zusammenhang zwischen Temperatur und Campylobacter-Inzidenz beim Menschen in England und Wales beobachtet [40]. Andere Studien konnten dies jedoch nicht bestätigen.

In Deutschland fielen im Jahr 2007 überdurchschnittlich hohe Campylobacter-Inzidenzen bereits im Frühjahr auf. Während in den Vorjahren die Inzidenz erst ab Mitte Mai deutlich anstieg, nahm in $2007 \mathrm{ab}$ Anfang April die Inzidenz signifikant zu (• Abb. 7). Dies ging einher mit ungewöhnlich warmen und trockenen Wetterbedingungen. So lag im April 2007 die durchschnittliche Tagestemperatur um $3^{\circ} \mathrm{C}$ höher als im langjährigen Mittel (• Abb. 7).

Auch wenn der saisonale Trend bei Salmonellen- und Campylobacter-Infektionen in den Industrieländern multifaktoriell bedingt ist, muss bei fortschreitender Erwärmung mit einer Zunahme der Erkrankungsfälle beim Menschen gerechnet werden. Schätzungen auf der Basis wissenschaftlicher Studien und Modellrechnungen gehen davon aus, dass ein durchschnittlicher Temperaturanstieg um $1^{\circ} \mathrm{C}$ zu einer Erhöhung der Inzidenz lebensmittelbedingter Gastroenteritiden um 4-5\% führt [41]. 


\section{Durch Wasser übertragene Infektionserreger und Toxine}

Eine Vielzahl von Infektionserregern kann über Wasser übertragen werden. Der Einfluss klimatischer Faktoren auf das Auftreten solcher Infektionen soll beispielhaft anhand der Infektionen durch Giardia lamblia und Kryptosporidien und durch Vibrionen illustriert werden.

Giardia lamblia und Kryptosporidien. Giardia lamblia und Kryptosporidien sind Zoonose-Erreger (Reservoirs: G. lamblia bei diversen Nutz-, Haus- und Wildtieren, Kryptosporidien bei Rindern und anderen Nutztieren), die Diarrhöen und Abdominalbeschwerden verursachen. Außer durch Schmierinfektionen und Lebensmittel werden sie auch durch orale Aufnahme von kontaminiertem Wasser übertragen.

Starke Regenfälle und Überschwemmungen können das Risiko einer Kontamination von Badegewässern, privaten Trinkwasserquellen und unter ungünstigen Umständen auch von Grundwasser beziehungsweise der öffentlichen Trinkwasserversorgung erhöhen. Eine Studie in USA hat einen statistisch signifikanten Zusammenhang zwischen StarkregenEreignissen und der Häufigkeit wasserbedingter Infektionsausbrüche gezeigt [42].

In Deutschland werden jedes Jahr mehrere tausend Giardia- und Kryptosporidien-Erkrankungsfälle gemeldet. Allerdings fehlen Studien zu den konkreten Risikofaktoren dieser Infektionen in Deutschland weitgehend. Abgesehen von vereinzelten wasserbedingten Ausbrüchen in den letzten Jahren liefert die Detailauswertung der Surveillance-Daten und eine Fall-Kontroll-Studie bislang keine Hinweise, dass die Übertragung durch Wasser für die Epidemiologie von Giardia- und Kryptosporidien-Infektionen derzeit eine größere Rolle spielt.

Dies könnte sich jedoch ändern, wenn häufigere Extremregen-Ereignisse zu einer stärkeren mikrobiologischen Belastung von Badegewässern und Trinkwasserquellen führen. Als Folge von früher einsetzenden und länger anhaltenden Wärmeperioden kann insgesamt die Exposition der Bevölkerung gegenüber $\mathrm{Ba}$ degewässern zunehmen.

Als weiterer Faktor ist die Verknappung von Wasser und eine daraus resultierende schlechtere Wasserqualität auf- grund länger anhaltender Trockenperioden zu berücksichtigen. Davon wird Deutschland aller Voraussicht nach in den nächsten Jahren nicht betroffen sein. Entsprechende Beispiele aus einigen Regionen Südeuropas zeigen aber, dass solche Probleme bei Zunahme von Wärme- und Trockenperioden auch in Deutschland auf längere Sicht nicht ausgeschlossen sind.

Vibrionen. Vibrionen können Durchfallerkrankungen, Wundinfektionen und Septikämien hervorrufen. Von den mehr als 200 Vibrio-cholerae-Serogruppen weltweit verursachen nur die choleratoxinproduzierenden Serogruppen O1 und O139 die klassische Cholera, die in Deutschland nur ausnahmsweise als importierte Erkrankung vorkommt. Weitere Vibrionen von klinischer Relevanz sind insbesondere Vibrio parahaemolyticus (Durchfallerkrankungen zum Beispiel nach Verzehr von Meeresfrüchten) und Vibrio vulnificus (Wundinfektionen, schwere Septikämien bei immunsupprimierten Patienten). Die meisten Vibrionen haben ihr Reservoir in flachem, brackigem Meerwasser. Sie vermehren sich besonders gut in Salzwasser (zum Teil aber auch in Binnenseen) bei Wassertemperaturen von über $20^{\circ} \mathrm{C}$. Diese Temperaturen werden in warmen Sommern auch in Ostsee und Nordsee über längere Zeiträume erreicht.

In den letzten Jahren sind in Mecklenburg-Vorpommern und SchleswigHolstein, aber auch in Dänemark, Südschweden und den Niederlanden wiederholt Patienten, die im Meer gebadet hatten, an Vibrionen-bedingten lokalen bis schweren systemischen Wundinfektionen erkrankt (V. vulnificus, V. cholerae, V.parahaemolyticus, V. alginolyticus) [43][44]. Gefährdet sind insbesondere ältere und immunsupprimierte Personen (zum Beispiel mit Vorerkrankungen wie Diabetes mellitus oder Lebererkrankungen), bei denen die Infektion auch tödlich verlaufen kann.

Bei steigenden Wassertemperaturen im Rahmen des Klimawandels ist in den deutschen Küstengewässern (aber zum Teil auch in Binnenseen) mit dem verstärkten Nachweis von Nicht-CholeraVibrionen im strandnahen Bereich und mit einer Zunahme der Erkrankungsfälle zu rechnen.
Cyanobakterien ("Blaualgen"). Cyanobakterien (ursprünglich Blaualgen genannt) kommen in Deutschland natürlicherweise in Binnenseen und der Ostsee vor. Bei bestimmten meteorologischen Bedingungen vor allem im Hochsommer können sie sich massenhaft vermehren und bei entsprechenden Windverhältnissen an Küsten und Badestrände angetrieben werden. Einige Arten von Cyanobakterien können Toxine bilden. Für Deutschland ist hierbei vor allem die Art Nodularia spumigena relevant, die das hepatotoxische Nodularin produziert. Die Cyanotoxine entfalten mögliche toxische Effekte, wenn sie oral aufgenommen werden (Verschlucken von Wasser). Der Hautkontakt kann durch die Wirkung von anderen Inhaltstoffen zu Juckreiz und Ausschlag führen. Die orale Aufnahme größerer Mengen von Cyanotoxinen kann theoretisch Vergiftungssymptome auslösen. Tatsächliche Intoxikationsfälle beim Menschen wurden für Deutschland bisher nicht beschrieben. Vor allem für Kleinkinder, die größere Wassermengen aufnehmen (zum Beispiel Badeunfälle), ist theoretisch nicht auszuschließen, dass es zu Vergiftungssymptomen kommt. In der internationalen Literatur wurde im Zusammenhang mit stärkerer Exposition gegenüber Cyanobakterien vor allem über gastrointestinale Symptome berichtet, die wenige Stunden nach Kontakt auftreten und drei bis fünf Tage anhalten können. Im Einzelfall ist bei diesen Symptomen die Ursachenbewertung schwierig. Bei sehr hoher Blaualgenkonzentration sind allerdings Badewarnungen bis hin zum Badeverbot sinnvoll.

\section{Handlungs- und Forschungsbedarf}

Die komplexen Zusammenhänge zwischen den klimatischen Bedingungen und deren Veränderungen und der Gesundheit der Bevölkerung müssen verstärkt erforscht werden, damit konkrete Gesundheitsrisiken frühzeitig erkannt werden und geeignete Gegenmaßnahmen eingeleitet werden können.

Bezüglich der Infektionskrankheiten besteht Handlungs- und Forschungsbedarf insbesondere in den Feldern Surveillance, Epidemiologie, Modellierung und Public 
Abb. 7 CampylobacterErkrankungen und mittlere Tagestemperatur, Januar bis Juni 2007, Deutschland

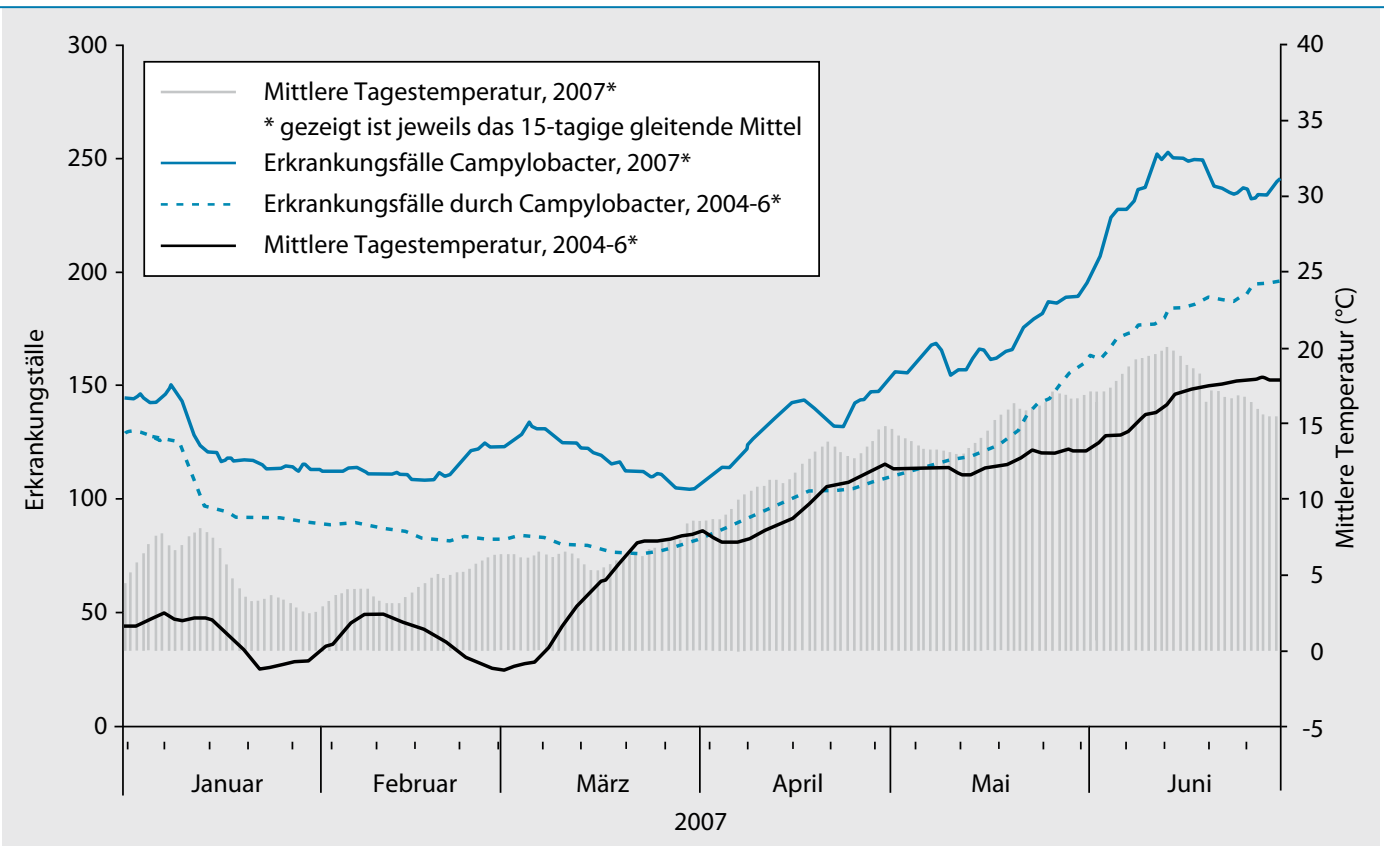

Derzeit ist im Einzelnen nicht absehbar, wie und in welchem Ausmaß klimatische Veränderungen das Auftreten von Infektionskrankheiten in Deutschland in den nächsten Jahrzehnten beeinflussen werden. Es müssen jedoch bereits jetzt anhand existierender Daten Analysen und Modellrechnungen zum Einfluss klimatischer Faktoren auf Infektionskrankheiten durchgeführt werden. Zusätzliche Daten müssen gewonnen werden, um epidemiologische Entwicklungen in Deutschland frühzeitig zu erkennen, ihre Ursachen zu verstehen und damit zukünftige Risiken besser abschätzen zu können. Hierfür sind vor allem nötig:

- Evaluierung des bestehenden Surveillance-Systems bezüglich seiner Fähigkeit klimasensitive einheimische (autochthone) und importierte Infektionen adäquat zu überwachen,

- Entwicklung geeigneter Strategien zur Früherkennung von Verdachtsfällen bzw. Erkrankungsfällen durch neu in Deutschland auftretende (nichtmeldepflichtige) Infektionserreger (inklusive verbesserte Ärzteausbildung),

- systematische Untersuchungen von Risikopopulationen/Sentinelpopulationen (Mensch, Tier, Vektoren) auf Prävalenz und Inzidenz von bestimmten klimasensitiven Infektionskrankheiten,

- mathematische Modellierung (inklusive Anwendung von Geografischen Informationssystemen),
- Entwicklung von Strategien und Projekten zur Prävention von Infektionen durch klimasensitive Erreger.

\section{Vektorüberwachung und Vektorkompetenz}

Für eine Abschätzung der Infektionsrisiken der durch Vektoren (zum Beispiel Mücken, Zecken, Nager) übertragenen Krankheiten ist es von großer Bedeutung, zuverlässige Informationen zur Verbreitung beziehungsweise Ausbreitung dieser Vektoren zu haben. Dies erfordert sehr genaue Kenntnisse über die Lebensbedingungen, die erfüllt sein müssen, damit die jeweiligen Vektoren ihre Lebens- und Vermehrungszyklen aufrechterhalten können. Derzeit liegen hinreichende Erfahrungen zu den erforderlichen Umweltbedingungen (Temperatur, Luftfeuchte, Nahrungsangebot et cetera) für die verschiedenen Vektoren vor. Allerdings sind komplexere Zusammenhänge, was das Vorkommen und die Ausbreitung von Vektoren angeht, noch nicht verstanden. So hängt die Vermehrung der Zecken stark mit der Dichte und Verbreitung geeigneter Nager und Wildtiere zusammen, die aufgrund des Nahrungsangebots und/ oder der Bejagung erheblich schwanken können. Inwieweit sich vorhandene Vektoren im Laufe des Klimawandels an veränderte Bedingungen anpassen werden beziehungsweise sich andere Vektoren, die besser an die neuen Bedingungen an- 
gepasst sind, einwandern werden, kann derzeit nicht beantwortet werden.

Ein weiterer Faktor ist die als Vektorkompetenz bezeichnete Fähigkeit von Mücken, Zecken, Nagern oder von anderen Vektoren, einen bestimmten Krankheitserreger so zu vermehren, dass eine Übertragung auf andere Wirtstiere möglich ist. Da diese Fähigkeit an sehr unterschiedliche Voraussetzungen sowohl auf Seite der Vektoren als auch der des jeweiligen Wirts gebunden ist, sind hierzu erforderliche Untersuchungen nicht einfach durchzuführen. Ob Übertragungen von Pathogenen zwischen Vektor und Wirt, die im Experiment gelingen, auch unter veränderten realen klimatischen Bedingungen eine Relevanz haben werden, bleibt fraglich.

Derzeit gibt es keine systematischen und flächendeckenden Untersuchungen über die Vektorausbreitung in Deutschland. Zwar existieren erste vielversprechende Ansätze für eine großflächige Untersuchung von Nagern auf Hantaviren in entsprechenden Netzwerken, allerdings fehlt es auch hier noch an Nachhaltigkeit. Andere Untersuchungen zur Verbreitung von Mücken, Sandfliegen oder Zecken konzentrieren sich auf Gebiete mit geeigneten klimatischen Voraussetzungen beziehungsweise auf bekannte Endemiegebiete. So konnte das Vorkommen von Leishmaniose übertragenden Sandmücken (Phlebotomen) im klimatisch geeigneten Oberrheingraben bestätigt werden. Für eine gezielte Risikoabschätzung zur Dynamik der Vektorausbreitung wäre eine systematischere und regelmäßige Analyse an allen potenziellen Verbreitungsgebieten notwendig. Hierzu würden auch gezielte Untersuchungen in der Umgebung möglicher Einfallstore entlang von Straßen, Häfen und Flughäfen gehören.

\section{Forschungsbedarf}

\section{Pathogenität}

Hier sind Studien notwendig zur Frage der Einschleppung, Etablierung, Evolution und der Pathomechanismen von Erregervarianten mit erhöhter Pathogenität (zum Beispiel in Deutschland verstärkt auftretende Hantaviren vom Typ Dobrava). Es ist zu klären, welche Faktoren auf Erregerseite und Wirtsseite die Pathoge- nität determinieren. Dies ist von besonderer Relevanz für Erreger, mit denen bisher nur eine Minderheit der deutschen Bevölkerung bei gelegentlichen Fernreisen in Kontakt gekommen ist (zum Beispiel West-Nile-Virus, tropische Viren wie Chikungunya-Virus, Dengue-Virus).

Es sollte auch untersucht werden, welche konkreten Faktoren (bessere ökologische Bedingungen wie Temperatur, Feuchtigkeit, Reservoirtiere, kompetente Vektoren) die Etablierung von Erregerspezies beziehungsweise Erregervarianten mit erhöhter Pathogenität begünstigen.

\section{Nachweismethoden}

Die Nachweismethoden für neu auftretende Erreger müssen schnell und von hoher Sensitivität und Spezifität sein, um die seltenen importierten Erreger zum Beispiel bei fieberhaften Krankheitsbildern nach Tropenaufenthalt frühzeitig zu diagnostizieren. Verfügbare diagnostische Verfahren müssen bezüglich der genannten Kriterien evaluiert und gegebenenfalls weiterentwickelt werden. Für die gleichzeitige Untersuchung von Blut und anderen Körperflüssigkeiten bzw. -materialien auf verschiedene Erreger kann der Einsatz von geeigneten Multiplex-Verfahren im Rahmen differenzialdiagnostischer Erwägungen sinnvoll sein.

\section{Impfstoffe und Medikamentenentwicklung}

Für verschiedene klimasensitive Erreger sind bisher keine wirksamen und gut verträglichen Impfstoffe verfügbar (Dengue, Chikungunya, West Nile, Malaria, Leptospirose). Während für einige Erreger zur Entwicklung von Impfstoffen bereits größere klinische Studien durchgeführt werden (Dengue, Malaria, West-Nile-Virus), befindet sich die Impfstoffentwicklung bei anderen Erregern erst im Anfangsstadium (Chikungunya).

Angesichts der besorgniserregenden Resistenzsituation bei einigen Erregern weltweit (zum Beispiel Malaria) ist auch die Entwicklung neuer, wirksamer und preiswerter Medikamente zur weltweiten Eindämmung der Infektionen eine ständige Herausforderung.

\section{Gesetze und Richtlinien}

\section{Infektionsschutzgesetz}

Die Surveillance von meldepflichtigen Erregern in Deutschland liefert auch zum Aspekt des Klimaeinflusses nützliche Daten zur Epidemiologie von Infektionskrankheiten in Deutschland. Grundlage dafür ist das IfSG, das am 1.1.2001 in Kraft trat.

Der Labornachweis von 47 Erregern ist gegenüber dem Gesundheitsamt namentlich meldepflichtig. Hinzu kommt die Meldepflicht für den klinisch tätigen Arzt (Praxis, Krankenhaus und andere) bei Verdacht, Erkrankung und Tod bezüglich bestimmter Infektionskrankheiten. Der Labornachweis von sechs weiteren Erregern wird nicht namentlich direkt an das RKI gemeldet. Das IfSG deckt die meisten klimasensitiven Erreger ab.

Ergänzungen des IfSG können für einige Erreger notwendig werden, die im $\mathrm{Zu}$ sammenhang mit klimatischen Veränderungen für Deutschland zunehmend relevant werden. Dies gilt unter anderem für Lyme-Borreliose, West-Nile-Virus, Leishmaniose, Amöbiasis, Vibrio vulnificus und andere Nicht-Cholera-Vibrionen.

\section{Internationale Gesundheits- vorschriften (International Health Regulations)}

Die weltweit wachsende Mobilität und der weiterhin zunehmende internationale Handel erhöhen das Risiko einer raschen Weiterverbreitung von Infektionserregern über große Entfernungen. Auswirkungen klimatischer Veränderungen auf das Auftreten von Infektionskrankheiten verschärfen diese Situation noch. Die Früherkennung und möglichst effiziente Kontrolle relevanter Public-HealthEreignisse (Ausbruchssituationen et cetera) erfordern einen schnellen und zuverlässigen Informationsaustausch und ein abgestimmtes Vorgehen bei der Infektionsüberwachung und -kontrolle auf internationaler Ebene. Die Staatengemeinschaft (58. Weltgesundheitsversammlung der WHO Juni 2005) hat mit der Verabschiedung der neuen Internationalen Gesundheitsvorschriften (IGV) auf diese Herausforderungen reagiert. Die IGV sind seit dem 15. Juni 2007 völkerrechtlich verbindlich. 
Die WHO hat nun deutlich mehr Möglichkeiten der Einflussnahme, und es werden Vorgaben hinsichtlich der Surveillance und Kontrolle von Ereignissen mit internationaler Tragweite gemacht, die von den Mitgliedsstaaten umzusetzen sind. Die IGV enthalten ein Bewertungsschema (Algorithmus), das von jedem Land bei Verdacht eines Ereignisses von internationaler Tragweite anzuwenden ist. Die Bewertung erfolgt anhand der Fragen: Sind die Auswirkungen des Ereignisses auf die öffentliche Gesundheit schwerwiegend? Ist das Ereignis ungewöhnlich oder unerwartet? Besteht ein erhebliches Risiko einer grenzüberschreitenden Ausbreitung? Besteht ein erhebliches Risiko der Beschränkung internationaler Reisen oder des internationalen Handels?

Liegt ein entsprechendes Ereignis vor, so ist dieses immer mit den bereits durchgeführten Maßnahmen innerhalb von 24 Stunden an die WHO zu melden. Die WHO sammelt darüber hinaus auch Informationen über gesundheitsrelevante Ereignisse aus anderen Quellen (internationale Informationssysteme wie ProMed, GPHIN et cetera) und bewertet die Gefahren einer (grenzüberschreitenden) Weiterverbreitung von Krankheiten.

Ansprechpartner für die WHO ist jeweils die nationale IGV-Anlaufstelle, für Deutschland das Lagezentrum des Bundesministeriums des Inneren. Soweit Infektionskrankheiten betroffen sind, koordiniert das RKI die Bearbeitung der Meldung sowie die notwendigen Maßnahmen. Durch Änderung des IfSG ( $\$ 12 \mathrm{Ab}$ satz 1) durch Verordnung vom Oktober 2006 wird sichergestellt, dass das jeweilige Gesundheitsamt über die zuständige Landesstelle dem RKI Informationen übermittelt, wenn nach IGV eine übertragbare Krankheit eine gesundheitliche Notlage von internationaler Tragweite darstellen könnte. Die Informationen betreffen das Auftreten der übertragbaren Krankheit oder Tatsachen, die zum Auftreten führen könnten, sowie die getroffenen Maßnahmen und sonstige Informationen, die zur Verhütung und Bekämpfung der übertragbaren Krankheit von Bedeutung sind. Neue Vorschriften der IGV zur Vektorkontrolle in Ein- und Ausfuhrhäfen (See- und Luftverkehr) sollen in Zukunft in Kraft treten.

\section{Ausbildung}

Aller Fortschritt durch Forschung und Wissenschaft über die gesundheitlichen Folgen eines Klimawandels kann nur dann den gewünschten Effekt in der täglichen medizinischen Praxis haben, wenn die neuen Erkenntnisse den Weg zum klinisch tätigen Arzt im Krankenhaus oder niedergelassenen Bereich finden. Für eine funktionierende Surveillance ist es eine "conditio sine qua non", dass die behandelnden Ärzte die bei einem Klimawandel zunehmenden Krankheiten in die Differenzialdiagnose aufnehmen und erkennen lernen. Der Schlüssel hierzu ist eine verstärkte Ausbildung des medizinischen Nachwuchses im Bereich Infektiologie und Tropenmedizin, aber auch die kontinuierliche Fort- und Weiterbildung der bereits tätigen Ärzte ist hier gefordert. Entsprechende Themen sollten in den Curricula der Medizinerausbildung stärker berücksichtigt werden.

\section{Resümee}

Eine Reihe von Studien hat gezeigt, dass in den letzten Jahren klimatische Faktoren das Auftreten von Infektionskrankheiten und Ausbrüchen signifikant beeinflusst haben. Viele Zusammenhänge zwischen dem verstärkten Auftreten von Infektionskrankheiten und klimatischen Veränderungen sind jedoch noch nicht im Detail untersucht. Deutschland muss aber bereits jetzt auf diese Problematik reagieren durch verstärkte Aktivitäten im Bereich Krankheits- und Vektorenüberwachung und gezielte Forschungsprogramme. Um den Herausforderungen gerecht zu werden, sind eine frühzeitige Festlegung der Forschungsprioritäten auf nationaler Ebene, eine enge Verzahnung der verschiedenen Fachdisziplinen (Humanmedizin, Veterinärmedizin, Mikrobiologie, Entomologie, Klimatologie, Biomathematik und andere) und eine intensive internationale Kooperation erforderlich.

\section{Korrespondenzadresse \\ Prof. Dr. K. Stark \\ Robert Koch-Institut \\ Postfach 650261, 13302 Berlin \\ starkk@rki.de}

\section{Hier steht eine Anzeige}

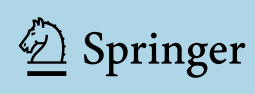




\section{Literatur}

1. Intergovernmental Panel on Climate Change (2007) Climate change 2007: The physical science basis. Contribution of working group I to the Fourth Assessment Report of the IPCC. http:// www.ipcc.ch/pdf/assessment-report/ar4/wg1/ar4wg1-chapter10.pdf

2. Roeckner $E$, Jacob D (2008) Der Klimawandel ist voll im Gange: Ein Überblick. In: Lozán JL, GraßI $\mathrm{H}$, Jendritzky $\mathrm{G}$ et al (Hrsg) Warnsignal Klima: Gesundheitsrisiken. Wissenschaftliche Auswertungen, Hamburg, S 19-34

3. Lindgren EK, Tälleklint L, Polfeldt T (2000) Impact of climate change on the northern latitude limit and population density of the disease-transmitting European tick Ixodes ricinus. Environ Health Perspect 108:119-123

4. RKI (2007) Lyme-Borreliose: Zur Situation in den östlichen Bundesländern. Analyse der Meldedaten aus dem 5-Jahreszeitraum von 2002 bis 2006. Epidemiol Bull 38:352-355

5. Dautel $\mathrm{H}$ et al (2007) Winter activity of Ixodes ricinus in a Berlin forest area. IX International Symposium on Tick-Borne Diseases, Jena, März 15-17

6. Poggensee $\mathrm{G}$ et al (2008) Lyme-Borreliose: Forschungsbedarf und Forschungsansätze. Ergebnisse eines interdisziplinären Expertentreffens am Robert Koch-Institut. Bundesgesundheitsbl Gesundheitsforsch Gesundheitsschutz (im Druck)

7. Abu Sin M, Stark K, van Treeck U et al (2007) Risk factors for hantavirus infection in Germany, 2005. Emerg Infect Dis 13:1364-1366

8. RKI (2007) FSME; Situation in Deutschland. Epidemiol Bull 15

9. Winter $\mathrm{CH}$, Brockmann SO, Piechotowski I et al (2009) Survey and case-control study - epidemic of Puumala virus infections in Germany 2007. Epidemiol Infect (in press)

10. RKI (2008) Hantavirus-Infektionen: Zur Zunahme der Erkrankungszahlen in Deutschland im Jahr 2007. Epidemiol Bull 19:147-152

11. Teichmann D, Gobels K, Simon J et al (2001) An severe case of leptospirosis acquired during an iron man contest. Eur J Clin Microbiol Infect Dis 20(2):137-138

12. Jansen A, Schoneberg I, Frank C et al (2005) Leptospirosis in Germany, 1962-2003. Emerg Infect Dis 11(7):1048-1054

13. Ciceroni L, Stepan E, Pinto A et al (2000) Epidemiological trend of human leptospirosis in Italy between 1994 and 1996. Eur J Epidemiol 16(1):7986

14. Desai S, van Treeck U, Lierz M et al (2009) Resurgence of field fever in a temperate country: an epidemic of leptospirosis among seasonal strawberry harvesters in Germany in 2007. Clin Infect Dis 48:691-697

15. Tarnvik A, Priebe HS, Grunow R (2004) Tularaemia in Europe: an epidemiological overview. Scand J Infect Dis 36(5):350-355

16. Grunow R, Priebe HS (2007) Tularämie - Zum Vorkommen in Deutschland. Epidemiol Bull 17:51-56

17. Stanek G (2008) Durch Zecken übertragbare Krankheitserreger in Mitteleuropa. WKWOA 117(11-12):373-380

18. Randolph S (2002) Predicting the risk of tick-borne diseases. Int J Med Microbiol 291 (Suppl 33):6-10

19. Petersen JM, Schriefer ME (2005) Tularemia: Emergence/re-emergence. Vet Res 36(3):455-467
20. Depoortere E, Coulombier D, ECDC (2007) Chikungunya risk assessment group (2006) Chikungunya risk assessment for Europe: recommendations for action. Euro Surveill 11:E060511.2. http://www. eurosurveillance.org/ew/2006/060511.asp\#2 (Accessed 29 August 2007)

21. Linke $S$, Niedrig M, Kaiser A (2007) Serological evidence of West Nile Virus infection in wild birds in Germany. Am J Trop Med Hyg 77(2):358-364

22. Zhou G, Minakawa N, Githeko AK, Yan G (2005) Climate variability and malaria epidemics in the highlands of East Africa. Trends Parasitol 21:54-56

23. Kampen H, Maier WA (2008) Wird die Malaria wieder eine Gefahr für Europa? In: Lozán JL, GraßI H, Jendritzky G et al (Hrsg) Warnsignal Klima: Gesundheitsrisiken. Wissenschaftliche Auswertungen, Hamburg, S 169-172

24. Schöneberg I, Stark K, Altmann D, Krause G (2008) Imported malaria in Germany - countries of infection and parasite species, 1993-2007. Gesundheitswesen 70:256-261

25. Krüger A, Rech A, Su XZ, Tannich E (2001) Two cases of autochthonous Plasmodium falciparum malaria in Germany with evidence for local transmission by indigenous Anopheles plumbeus. Trop Med Int Health 6:983-985

26. Cortes S, Afonso MO, Alves-Pires C, Campino L (2007) Stray dogs and leishmaniasis in urban areas, Portugal. Emerg Infect Dis 13:1431-1432

27. Harms-Zwingenberger G, Bienzle U (2007) Nach Deutschland importierte Leishmaniosen. Dtsch Ärztebl 104:3108-3113

28. Bogdan C, Schönian G, Bañuls AL et al (2001) Visceral leishmaniasis in a German child who had never entered a known endemic area: case report and review of the literature. Clin Infect Dis 32:302306

29. Koehler K, Stechele M, Hetzel U et al (2002) Cutaneous leishmaniosis in a horse in southern Germany caused by Leishmania infantum. Vet Parasitol 109:9-17

30. Failloux AB, Vazeille M, Rodhain F (2002) Geographic genetic variation in populations of the dengue virus vector Aedes aegypti. J Mol Evol 55:653-663

31. Reiter P, Fontenille D, Paupy C (2006) Aedes albopictus as an epidemic vector of chikungunya virus: another emerging problem? Lancet Infect Dis 6:463-464

32. Donoso Mantke O, Schädler R, Niedrig M (2008) Survey on cases of Tick borne encephalitis in European countries. Eurosurveillance 13(17) pii:18848

33. Boromisa RD, Rai KS, Grimstad PR (1987) Variation in the vector competence of geographic strains of Aedes albopictus for dengue 1 virus. J Am Mosq Control Assoc 3:378-386

34. Moore CG, Francy DB, Eliason DA, Monath TP (1988) Aedes albopictus in the United States: rapid spread of a potential disease vector. J Am Mosq Control Assoc 4(3):356-361

35. Rezza G, Nicoletti L, Angelini R et al (2007) CHIKV study group. Infection with chikungunya virus in Italy: an outbreak in a temperate region. Lancet 370(9602):1840-1846

36. Baqar S, Hayes CG, Murphy JR, Watts DM (1993) Vertical transmission of West Nile virus by Culex and Aedes species mosquitoes. Am J Trop Med Hyg 48:757-762

37. Bakonyi T, Ivanics E, Erdélyi K et al (2006) Lineage 1 and 2 strains of encephalitic West Nile virus, Central Europe. Emerg Infect Dis 12(4):618-623

38. RKI (2008) Campylobacter-Enteritis. In: RKI (Hrsg) Infektionsepidemiologisches Jahrbuch meldepflichtiger Krankheiten für 2007. Eigenverlag, Berlin, S 57-61
39. Bentham G, Langford IH (2001) Environmental temperatures and the incidence of food poisoning in England and Wales. Int J Biometeorol 45:22-26

40. Louis VR, Gillespie IA, O'Brien SJ et al (2005) Temperature-driven Campylobacter seasonality in England and Wales. Appl Environ Microbiol 71:8592

41. Health Protection Agency (2008) Health effects of climate change in the United Kingdom 2008. Department of Health Report, London

42. Curriero F, Patz JA, Rose JB, Lele S (2001) The association between extreme precipitation and waterborne disease outbreaks in the United States, 1948-1994. Am J Public Health 91:1194-1199

43. RKI (2004) Vibrio-vulnificus-Infektion: Zwei schwere Erkrankungsverläufe - Fallberichte. Epidemiol Bull 13:105-106

44. RKI (2006) Hinweis auf mögliche Wundinfektionen durch Vibrio vulnificus bei Kontakt mit warmem Meerwasser. Epidemiol Bull 32:277

45. Jansen A, Frank C, Koch J, Stark K (2009) Surveillance of vector-borne diseases in Germany: trends and challenges in the view of disease emergence and climate change. Parasitol Res (in press)

46. Eckmanns T, Krause G (2008) Surveillance von Infektionskrankheiten. In: Lozán JL, GraßI H, Jendritzky G et al (Hrsg) Warnsignal Klima: Gesundheitsrisiken. Wissenschaftliche Auswertungen, Hamburg, S 337-340 